\title{
Cómo hacer la historia de la homosexualidad masculina'
}

\section{David M. Halperin}

La historia de la sexualidad constituye ahora una disciplina académica tan respetable o, al menos, tan bien establecida, que quienes la practican ya no sienten más la presión de tener que defender la empresa, o rescatarla de las sospechas de ser una palpable absurdidad. La propia frase "historia de la sexualidad" sonaba como una contradicción en sus términos: ¿cómo, después de todo, podría tener la sexualidad una historia? Hoy en día, por el contrario, estamos tan acostumbrados a la noción de que la sexualidad tiene ciertamente una historia que, a menudo, no nos preguntamos qué tipo de historia es la que tiene la sexualidad. Cuando tales cuestiones se presentan, se las trata superficialmente en el curso del carraspeo metodológico que los historiadores ritualmente performan en los párrafos iniciales de sus artículos académicos. Recientemente este ejercicio ha tendido a incluir referencias más o menos obligatorias a los problemas alguna vez causados a los historiadores, hace mucho mucho tiempo, en un país muy muy lejano, por teóricos que argumentaron que la sexualidad estaba socialmente construida, una idea interesante en su momento y lugar, pero que fue llevada a extremos delirantes y que ya no goza de demasiado crédito ${ }^{2}$. Con el potencial disruptivo de estas cuestiones metahistóricas cuidadosamente relegadas al pasado, el historiador de la sexualidad puede regresar al trabajo que tiene entre manos.

${ }^{1}$ El título de mi artículo constituye un homenaje al trabajo de Arnold I. Davidson, que ha dado forma a mi propio trabajo de manera consistente, duradera y poderosa; ver, especialmente, sus ensayos "How to Do the History of Psychoanalysis: A Reading of Freud's Three Essays on the Theory of Sexuality" (1987); "Sex and the Emergence of Sexuality" (1987); y "Closing Up the Corpses: Diseases of Sexuality and the Emergence of the Psychiatric Style of Reasoning" (1990). En mi trabajo reciente sobre la historia de la sexualidad, particularmente en el presente artículo y en "Forgetting Foucault" (en este mismo volumen) [N. de Ixs trad. de donde también tomamos el presente capítulo para su traducción], he vuelto a un conjunto de temas que el trabajo de Davidson me facilitó por primera vez y sobre los cuales he reflexionado durante toda una década.

Muchas personas han discutido conmigo las ideas que abordo en este ensayo; no puedo enumerar aquí todos los nombres, como me gustaría hacerlo. Pero debo agradecer a Patricia Crawford y Hilary Fraser, quienes me invitaron a participar en su Australian Academy on the Social Sciences Workshop "Gender, Sexualities, and Historical Change", University of Western Australia, 31 de julio-1 de agosto de 1998. Las discusiones entre los miembros de ese taller me sirvieron de estímulo para este ensayo. Estoy particularmente en deuda, en este sentido, con Judith M. Bennett.

Este ensayo fue escrito para su presentación en la conferencia "Sex and Conflict: Gay and Lesbian Studies in the Humanities and Social Sciences", Lund University, 9-10 de octubre de 1998. Quiero agradecer a Eva Österberg y Johanna Esseveld por darme la oportunidad para presentar mi trabajo, y a Martha Vicinus y Lillian Faderman, mis compañeras de sesión, por alentarme a perseverar en él.

Finalmente, quisiera agradecer a George E. Haggerty, cuyo trabajo y conversaciones me impulsaron a abordar algunas de esas ideas. Ver su Men in Love: Masculinity and Sexuality in the Eighteenth Century (1999), que ofrece una solución refrescantemente distinta a la propuesta aquí para una pregunta similar sobre cómo hacer la historia de la homosexualidad masculina.

Algunos de los materiales y de la argumentación presentada aquí aparecieron también en mi entrada "Sex, Sexuality, Sexual Classification", en Critical Terms for Gender Studies (compilado por Simpson y Herdt, finalmente publicado en 2014 por la University of Chicago Press).

${ }^{2}$ Ver, por ejemplo, Murray (1996), o el artículo, por demás excelente, de Clark (1996). 
Pero este nuevo consenso y el sentido de clausura teórica que lo acompaña es prematuro. Creo que es más útil que nunca preguntar cómo es que la sexualidad puede tener una historia. Sin duda, el punto crucial de una pregunta así no consiste en registrar el escepticismo y la incredulidad de quien pregunta (como si se preguntara: ¿cómo podría ser posible en la tierra una cosa así?) sino inquirir más de cerca en las modalidades del ser histórico que posee la sexualidad: preguntar cómo exactamente -en qué términos, por virtud de qué temporalidad, en cuáles de sus dimensiones o aspectostiene la sexualidad una historia.

Esa pregunta, por supuesto, ya ha sido hecha de muchas maneras, cada una de ellas manifestando una estrategia diferente para articular en la historia de la sexualidad la relación entre continuidad y discontinuidad, identidad y diferencia. El debate construccionista-esencialista de finales de la década de 1980 podría verse como un esfuerzo particularmente vigoroso por forzar una solución a esta pregunta, pero incluso después de que los construccionistas declararan haberlo ganado, y de que los esencialistas declararan haber expuesto el mal trabajo producido por él, y de que todos los demás se mostraran agotados, las cuestiones básicas sobre la historicidad de la sexualidad han permanecido. De hecho, la investigación actual sobre historia de la sexualidad todavía parece suspendida en el énfasis entre los dos polos de la identidad y la diferencia, que en mi punto de vista representan meramente versiones reformuladas de las antiguas posiciones esencialistas y construccionistas. Sin embargo, sería prudente reformular la cuestión en términos menos polémicos o anticuados reconociendo que cualquier intento adecuado por describir la historicidad de la sexualidad tendrá que centrarse tanto en algunas estrategias para contemplar los aspectos de la vida sexual que parecen persistir a través del tiempo como en las amplias diferencias entre formas históricamente documentadas de la experiencia sexual. Los modelos analíticos actuales que intentan hacer esto identificando cambios en las categorías o clasificaciones de una sexualidad, por lo demás inalterable, o en una distinción histórica entre actos sexuales premodernos e identidades sexuales modernas simplemente no pueden capturar la complejidad de los temas en juego en las nuevas historias de la subjetividad que están disponibles hoy ${ }^{3}$.

Las tensiones entre énfasis interpretativos en continuidad y discontinuidad, en identidad y diferencia, aparecen con una intensidad casi dolorosa en la historiografía de la homosexualidad. Reflejan no solo las altas apuestas políticas en cualquier proyecto contemporáneo que involucre la producción de representaciones de la homosexualidad sino también la irreductible incertidumbre definicional sobre lo que la homosexualidad es realmente en sí misma ${ }^{4}$. Quizás la más clara y explícita articulación

${ }^{3} \mathrm{O}$ eso discuto en los capítulos "Historizing the Subject of Desire" y en "Forgetting Foucault" de How to do the History of Homosexuality (Halperin, 2002). Para un bastante diferente pero persuasivo y poderoso argumento sobre la importancia de enfatizar continuidades en la historia de las mujeres, ver Bennett (1997).

${ }^{4}$ La definición de la existencia de una incerteza definicional irreductible es el logro central, invalorable de la Epistemología del armario (1990) de Eve Kososfky Sedgwick. Como se hará evidente, tomo en cuenta sus críticas a mi obra anterior, One Hundred Years of Homosexuality and Other Essays on Greek Love (1990), aplicando su lección acerca de la irresoluble contradicción entre lo que muy rápidamente llamamos "la homosexualidad tal como hoy la conocemos". Al mismo tiempo, sin embargo, continuaré insistiendo en la documentada existencia de lo que llama ella, sarcásticamente, "un Gran Cambio de Paradigma" en la historia de la homosexualidad, es decir, la emergencia de discursos sobre la homosexualidad en el periodo moderno. Lejos de ver un conflicto entre una indagación histórica dentro de la construcción de la 
de las consecuencias de esta incerteza para los historiadores se encuentre en la introducción a Hidden from History: Reclaiming the Gay and Lesbian Past [Escondidos de la historia: Reclamando el pasado gay y lesbiano], la pionera antología de historia gay y lesbiana publicada en 1989: "Se considera que la sexualidad genital del mismo sexo, el amor y la amistad, la no-conformidad de género, y una cierta estética o perspectiva política poseen alguna relación (a menudo ambigua y siempre discutida) con ese complejo de atributos que hoy designamos como homosexualidad. Mucha investigación histórica ha consistido en un esfuerzo por localizar los antecedentes de aquellas características que un historiador dado cree que son constitutivas de la identidad gay contemporánea, ya sean actos sodomíticos, travestismo [cross dressing], o amistades íntimas" (Duberman, Vicinus y Chauncey, 1989: 8). Si la identidad gay o lesbiana contemporánea parece flotar en suspenso entre discursos diferentes y discontinuos de sodomía, inversión de género y amor por el mismo sexo, lo mismo puede ser dicho, incluso más enfáticamente, sobre la identidad homosexual cuando intentamos remontarla hacia atrás en el tiempo. La esencia de la aproximación construccionista a la historia de la homosexualidad, después de todo, fue argumentar que la homosexualidad es una construcción moderna no porque los actos entre personas del mismo sexo o las etiquetas eróticas no existieran antes de 1869, cuando el término "homosexualidad" apareció impreso por primera vez, sino porque ninguna categoría de discurso o experiencia existió en los mundos premodernos y no occidentales que comprendiera exactamente el mismo rango de comportamientos sexuales entre personas del mismo sexo, deseos, psicologías y socialidades, así como las diversas formas de desviación de género que ahora caen dentro de los amplios límites definicionales de la homosexualidad. Algunas categorías de identidad anteriores vinculadas a las prácticas sexuales entre personas del mismo sexo ocuparon algunos de los territorios ahora reclamados por la homosexualidad; otros atraviesan la frontera entre homosexualidad y heterosexualidad. Algunas de estas categorías de identidad persistieron en formas variadas por cientos de años antes de que el término o concepto moderno de homosexualidad fuera inventado. Es bastante posible que la actual incertidumbre definicional sobre lo que la homosexualidad es o la incertidumbre sobre qué características son constitutivas de la identidad lesbiana o gay sea el resultado lógico de este largo proceso de acumulación y adición. La historia de los discursos pertenecientes a formas de intimidad masculina puede ser especialmente reveladora porque tales discursos han sido extensa y complejamente elaborados a lo largo del tiempo y condensan una gran cantidad de sistemas de pensamiento en cuya intersección nos encontramos, ahora, a nosotros mismos.

A continuación, ofrezco lo que considero una nueva estrategia para aproximarse a la historia de la sexualidad en general y a la historia de la homosexualidad masculina en particular. Mi estrategia está diseñada para rehabilitar un acercamiento construccionista a la historia de la sexualidad modificado,

homosexualidad y un análisis discursivo de las contradicciones de las modernas nociones de homosexualidad, veo tal indagación histórica como una investigación provechosa para la incoherencia imposible de ser erradicada de la noción moderna. El propio trabajo de Sedgwick, de hecho, me ha permitido llevar las críticas históricas y discursivas de la homosexualidad hacia un ajuste más detenido y sistemático. 
reconociendo sin inconvenientes la existencia de continuidades transhistóricas, reintegrándolas en el marco del análisis y reinterpretando su significación dentro de una comprensión genealógica de la emergencia de la (homo)sexualidad en sí misma. Una historia construccionista de la (homo)sexualidad, según mi punto de vista, puede contemplar fácilmente tales continuidades y necesita no tener miedo de o avergonzarse por ellas.

Comienzo donde todas las historias de la homosexualidad deberían comenzar (les guste o no), es decir, con la noción moderna de homosexualidad, que explícita o implícitamente, define los horizontes de nuestro universo conceptual inmediato e inevitablemente le da forma a nuestras indagaciones sobre comportamiento y deseo sexual entre personas del mismo sexo en el pasado. Si no podemos, simplemente, escapar de la tiranía conceptual de la homosexualidad mediante alguna proeza de rigor académico (como alguna vez pensamos que podríamos hacer) -a través de una insistente suspensión metodológica de las categorías modernas; por una determinación austeramente historicista en identificar y poner entre paréntesis nuestra propias presuposiciones ideológicas de modo de describir fenómenos anteriores en toda su irreductible especificidad cultural y pureza temporalpodemos, al menos, insistir en tomar nuestras categorías tan seriamente que se puedan magnificar sus propias contradicciones internas, hasta el punto de que esas contradicciones se conviertan en analíticamente informativas. Y si realmente hacemos el esfuerzo por aplicar al pasado nuestras definiciones modernas de homosexualidad, pondremos sobre ellas tanta presión heurística que acabarán por disolverse, revelando la forma de otras categorías, discursos, lógicas y coherencias anteriores.

Observar la desintegración de nuestros propios conceptos conforme los remontamos en el tiempo puede ser el punto de partida de una indagación dentro de la alteridad del pasado. Un análisis genealógico de la homosexualidad comienza con nuestra noción contemporánea de la homosexualidad, tan incoherente como esta pueda ser, no solo porque tal noción inevitablemente enmarca toda posible indagación de las expresiones sexuales entre personas del mismo sexo en el pasado, sino también porque su misma incoherencia registra los trazos de su propia evolución histórica. De hecho, es esta incoherencia, ubicada en el núcleo de la noción moderna de homosexualidad, la que suministra la más elocuente indicación de la acumulación histórica de nociones discontinuas que se albergan en su engañosa unidad. Los genealogistas intentan deslindar esas nociones trazando sus historias por separado, así como el proceso de sus interrelaciones, sus cruces y, a fin de cuentas, su inestable convergencia en la actualidad.

Por supuesto, hablar de convergencia en este contexto significa únicamente describir cómo funciona el concepto moderno de homosexualidad; no significa suscribir una creencia en ese funcionamiento. No significa, en consecuencia, reducir las heterogeneidades de la existencia cuir en el presente o en el pasado a un "principio dominante que habla por un todo ya dado" sino, más bien, de mostrar cómo la noción moderna de homosexualidad ha llegado a desempeñar el rol de un principio semejante (Chakrabarty, 2000: 107). Quisiera evitar la implicación de que analizando el triunfalismo de una categoría discursiva moderna estoy en cierto modo participando de ese triunfalismo. Por el contrario, quisiera enfatizar la particularidad de la "homosexualidad" como una formación singular, 
distintiva, que pretende representar todas las expresiones de sexualidad del mismo sexo, una perspectiva parcial que declara abarcar el todo. Mi respuesta consiste en des-idealizar la homosexualidad a fin de retornar a su contingencia y especificidad cultural.

Con este objetivo intentaré describir muy tentativamente, muy especulativamente, algunos discursos, prácticas, categorías, modelos, patrones (no estoy realmente seguro de cómo llamarlos) pre-homosexuales importantes, y bosquejar sus similitudes y diferencias con lo que actualmente se conoce con el nombre de homosexualidad. Hago esto con el objetivo de apuntar a un proyecto genealógico más amplio que otros, espero, corregirán y completarán. El proyecto que yo concibo necesita ser sistemático en la distinción de tradiciones anteriores, pre-homosexuales de discurso homosexual, tanto entre ellas, como con respecto a los discursos modernos de homosexualidad, notando, al mismo tiempo, solapamientos y características comunes. Necesita describir esas diferentes categorías en toda su riqueza y construir cada una de ellas con la mayor especificidad posible, dando cuenta al mismo tiempo de sus interrelaciones. $Y$ necesita identificar rupturas dentro de cada una de esas tradiciones discursivas: fracturas, transformaciones, reconfiguraciones, de modo de poder evidenciar las heterogeneidades contenidas dentro de las extensas historias de sus respectivas evoluciones. Tal proyecto, en caso de ser exitoso, sería capaz de capturar el juego de identidades y diferencias dentro de la multiplicidad sincrónica de tradiciones de discursos diferentes pero simultáneas que han existido a través del tiempo, así como el juego de identidades y diferencias a través de las diversas transiciones diacrónicas dentro de cada una de esas tradiciones en el curso del tiempo, mientras se lleva a primer plano la significativa ruptura efectuada durante las últimas tres o cuatro centurias a causa de la emergencia de los discursos de la (homo)sexualidad en sí misma.

El proyecto que he imaginado y descrito no es una invención totalmente original de mi parte. Previamente, historiadores y sociólogos han identificado cuatro modelos principales de acuerdo con los cuales los comportamientos sexuales entre personas del mismo sexo han sido culturalmente construidos alrededor del mundo (diferencia de edad, rol específico, travestismo, homosexualidad). Y esos cuatro modelos revelan algunas correspondencias obvias con las categorías empleadas en la genealogía de la homosexualidad masculina que estoy a punto de bosquejar ${ }^{5}$. Mi propia aproximación se

${ }^{5}$ Ver Trumbach (1977), Adam (1986 y 1985), Herdt (1987 y 1997) y Greenberg (1998). No todos los autores emplean una taxonomía cuádruple, y utilizan nombres diferentes para sus categorías. Greenberg habla de tipos "transgenéricos", "transgeneracionales" e "igualitarios" (los dos últimos términos son, desde mi punto de vista, confusos).

Finalmente, en una serie de artículos y libros que se remonta a los años 70, Stephen O. Murray ha venido definiendo y refinando los modelos sociológicos o tipológicos de acuerdo con las formas de comportamiento masculino homosexual que se han elaborado e institucionalizado alrededor del mundo: para su más reciente y comprehensivo tratamiento de este tópico, ver Murray (2000), especialmente las páginas 1-21, donde diferencia entre organizaciones de la homosexualidad "estratificadas por edad", "estratificadas por género", e "igualitarias (gais o lesbianas)". Murray hace la aclaración importante y fundamental de que "hay diversidad [en comportamiento y clasificación homosexual] pero hay solo unos pocos patrones recurrentes. Relativamente pocas de las estructuraciones imaginables de sexo homosexual reaparecen en el panorama de las sociedades conocidas... No hay cientos, ni siquiera docenas, de organizaciones sociales diferentes de las relaciones del mismo sexo en las sociedades humanas... Solo unos pocos sistemas de categorización reaparecen a través del espacio y el tiempo" (Murray, 2000: 1-2). Para advertencias anteriores sobre este punto clave en los trabajos previos del autor, ver Murray $(1984,1989,1995)$. En el último ensayo, Murray propuso una tipología 
distingue, creo, por ser explícitamente genealógica más que sociológica o conductual (o incluso, en un sentido estricto, histórica), y por hacer visible una serie de figuras discursivas inmanentes en las tradiciones sociales y culturales de Europa en particular. (Focalizo aquí en la historia de los discursos europeos porque intento construir la genealogía de la noción europea -es decir, homosexualidad-, pero incluyo material no europeo cuando me parece pertinente). Mis más inmediatos precursores son los editores de Hidden from History citados anteriormente: los tres modelos de homosexualidad que ellos enumeran -"sexualidad genital del mismo sexo" (o "actos sodomíticos"), "amor y amistad" (o "amistades íntimas") y "no conformidad de género" (o "travestismo")- anticipan muy de cerca las divisiones que propondré aquí.

Argumentaré, en todo caso, que no hay algo así como una historia de la homosexualidad masculina. Al menos, no hay tal cosa como una historia singular o unitaria de la homosexualidad masculina. En su lugar, hay historias para escribirse o al menos cuatro diferentes pero simultáneas categorías o tradiciones de discursos concernientes a aspectos de lo que ahora definimos como homosexualidad. Cada una de esas tradiciones tiene su propia consistencia, autonomía, densidad, particularidad y continuidad en el tiempo, aunque cada una ha experimentado también diversas fracturas o rupturas. Cada una ha subsistido más o menos independientemente de las otras, aunque hayan interactuado frecuentemente entre sí, y contribuido a constituirse unas a otras a través de distintas exclusiones. Sus historias individuales, así como la historia de sus interrelaciones, han sido oscurecidas pero no reemplazadas por la emergencia reciente de los discursos sobre la (homo)sexualidad. De hecho, lo que la "homosexualidad" significa hoy es un efecto del proceso acumulativo de superposición y adición histórica. Un resultado de este proceso histórico es lo Eve Kosofsky Sedgwick memorablemente llama "la coexistencia no racionalizada de diferentes modelos" de sexo y género en la actualidad (Sedgwick, 1990: 47). Creo que me encuentro en la posición de ofrecer, como hipótesis, una explicación histórica para el fenómeno que Sedgwick describió tan brillantemente.

A mi modo de ver, si nuestra "comprensión de la definición homosexual... se organiza alrededor de una radical e irreductible incoherencia", debida a la "no racionalizada coexistencia de diferentes modelos" de sexo y género, como afirma Sedgwick, es porque hemos retenido al menos cuatro modelos pre-homosexuales de desviación masculina sexual y de género, todos ellos derivados de un antiguo sistema que privilegia el género sobre la sexualidad, junto a ( $y$ a pesar de su flagrante conflicto con) un modelo homosexual más nuevo, derivado de un sistema más reciente y comparativamente anómalo que privilegia la sexualidad sobre el género (Sedgwick, 1990: 47 y 85). Si tal explicación es correcta, entonces una genealogía del discurso homosexual contemporáneo -es decir, una crítica histórica de la categoría de homosexualidad, como la que propongo emprender- puede sostener y expandir significativamente la

cuádruple, que incluye una categoría denominada "organización de la homosexualidad definida por profesión"; en su libro más reciente, Homosexualities, esta categoría ha colapsado dentro de la homosexualidad "estratificada por género". 
influyente crítica discursiva de Sedgwick a la categoría de homosexualidad en Epistemología del armario y proporcionar un fundamento histórico retrasado y muy necesario ${ }^{6}$.

Las cuatro categorías pre-homosexuales de desviación masculina sexual y de género que he identificado hasta aquí pueden ser descritas, muy provisionalmente, como categorías de (1) afeminamiento, (2) pederastia o sodomía activa, (3) amistad o amor masculino y (4) pasividad o inversión. Una quinta categoría, la de homosexualidad, es -a pesar de sus ocasionales figuraciones en discursos anteriores (que sería valioso trazar, aunque no haré eso aquí) - una adición reciente. Me concentraré en la historia de los discursos porque lo que estoy intentando trazar es una genealogía de los discursos modernos sobre homosexualidad, sin embargo, como se volverá evidente, esto no significa excluir la historia de las prácticas, cuya relación con la historia de los discursos aguarda una consideración más profunda. En todo caso, mi objetivo principal es producir un modelo, articular un patrón de discurso, no escribir una historia social o una fuente descriptiva de prácticas sexuales. Incluso haciendo eso, no intentaré aquí recuperar la variedad de silencios discursivos, los conocimientos subyugados, las voces no representadas que deben figurar de manera significativa, o al menos ser tomadas en cuenta, en cualquier historia sustantiva de la homosexualidad masculina. La genealogía preliminar ofrecida aquí inevitablemente sobrerrepresentará discursos dominantes o de élite, aunque sin limitarse enteramente a ellos, y como tal será inevitablemente imparcial e incompleta. Una investigación genealógica más completa debería superar, en la medida de lo posible, tales limitaciones.

Quiero enfatizar desde el comienzo que los nombres que he elegido para las primeras cuatro de esas categorías son heurísticos, tentativos y ad hoc. Mis designaciones no son propiamente descriptores históricos; ¿cómo podrían serlo, desde el momento en que las cuatro categorías atraviesan periodos históricos geografías y culturas? Mis definiciones de las cuatro primeras categorías tampoco explicarán los significados históricos de los nombres que les he dado. Por ejemplo "sodomía", esa "categoría tan confusa", según Foucault (2005: 23) ${ }^{7}$, fue históricamente aplicada a la masturbación, el sexo oral, el sexo anal y las relaciones entre personas del mismo sexo, entre otras cosas, pero mi segunda categoría se refiere a algo mucho más específico, no porque no tenga conciencia de la pluralidad de significados históricos de "sodomía" sino porque empleo el término "sodomía activa" específicamente en una forma transhistórica, para denominar cierto modelo o estructura de relaciones homosexuales masculinas para las cuales no existe un único nombre adecuado. Esto es desafortunado, pero por el momento no veo alternativa. Hecha esta advertencia final, déjenme comenzar.

\footnotetext{
${ }^{6}$ Respondo con mayor detalle a la crítica de Sedgwick a la historia construccionista en la introducción a How to Do the History of Homosexuality (2002: 1-23).

${ }^{7}$ Esta y otras citas corresponden a la traducción española de Histoire de la sexualité l: La volonté de savoir consignada en la bibliografía, y no a la traducción inglesa manejada por Halperin (nota de los traductores).
} 
El afeminamiento ha funcionado a menudo como un marcador de la así llamada inversión sexual en el hombre, o transgenerismo, o inversión del rol sexual, y por lo tanto (de acuerdo con una muy específica e históricamente contingente lógica cultural) de deseo homosexual. Sin embargo, es útil distinguir afeminamiento de pasividad masculina, de inversión, y de homosexualidad. Particularmente, el afeminamiento debería ser claramente distinguido de la elección de objeto o preferencia sexual por el mismo sexo entre los varones -y no solo por las bien ensayadas razones de que es posible, para los hombres, ser afeminados sin ser homosexuales y ser homosexuales sin ser afeminados-. Más bien, el afeminamiento merece ser tratado independientemente porque fue por mucho tiempo definido como síntoma de un exceso de lo que ahora llamaríamos deseo tanto heterosexual como homosexual. Es, en consecuencia, una categoría en sí misma.

El afeminamiento no siempre implicó homosexualidad. En diversas tradiciones culturales europeas los hombres podían ser designados como "suaves" o "no masculinos" (malthakos en griego, mollis en latín y lenguas romances derivadas), tanto porque eran invertidos o afectados [pathics] -es decir, femeninos, o transgéneros, y les gustaba ser penetrados por otros hombres- o porque, por el contrario, eran mujeriegos, es decir, se desviaban de las normas de género en la medida en que preferían la suave opción del amor a la dura opción de la guerra. En la cultura de las élites militares de Europa, al menos del mundo antiguo a través del Renacimiento, la masculinidad normativa a menudo conllevaba austeridad, resistencia al apetito y dominio del impulso hacia el placer. (El ideal estadounidense alguna vez popular del Gran Hombre del Campus, el jugador de fútbol que llega a disfrutar ilimitadamente de su amor por las duchas calientes, la cerveza fría, los autos rápidos y las mujeres aún más rápidas, podría aparecer en este contexto no como un emblema de la masculinidad sino como su opuesto degradado, como un monstruo de afeminamiento). Un hombre demostraba su verdadero coraje en la guerra, o eso solía pensarse, y más generalmente en luchas con otros hombres por el honor -en políticas, negocios y otras empresas competitivas-. Aquellos hombres que rechazaban aceptar el reto, que abandonaban las sociedades competitivas de hombres para hombres por la sociedad amorosa de las mujeres, que perseguían una vida de placer, que hacían el amor en vez de la guerra; ellos encarnaban el clásico estereotipo de afeminamiento. Este estereotipo parece pervivir en el sur de EE. UU., donde un "provinciano cuir" es definido como "un muchacho de Alabama al que le gustan más las chicas que el fútbol" (Daniell, 1984: 71). También sobrevive y muy bien en la Australia anglo-celta, donde un tipo de verdad supuestamente evita la compañía de mujeres y prefiere pasar el rato con sus compañeros: así es como puedes estar seguro de que es heterosexual.

Este estereotipo, que ciertamente no cuadra bien con las nociones recientes de hetero y homosexualidad, se remonta más atrás en el tiempo. Para los antiguos griegos y romanos, un hombre que disfrutaba de su gusto por el placer sexual con mujeres no necesariamente aumentaba su virilidad, sino que a menudo la socavaba. Para agradar a una mujer, tal hombre tuvo probablemente que hacer un esfuerzo para parecer delicado en vez de rudo, gracioso en vez de poderoso, puede que incluso haya compuesto ese estilo afeminado usando maquillajes y perfumes, elaborado acicalamiento y prominente joyería. En un diálogo atribuido a Luciano, que presenta un debate entre dos hombres sobre si las mujeres o los varones son los mejores vehículos del placer erótico masculino, es el 
abogado de los varones el que es retratado como hiperviril, mientras que el defensor de las mujeres, un joven bien parecido, es descrito exhibiendo "un hábil uso de cosméticos, con el fin de resultar más atractivo para las mujeres" (Pseudo-Lucian, 1967). De modo similar, el estereotipo de un adúltero en la antigua tradición literaria griega puede ser juzgado a partir de la siguiente descripción, en una novela del prosista Caritón [Quéreas y Callíroe], de un hombre que flagrantemente exhibe todos los marcadores canónicos que identifican el adulterio: "su pelo era reluciente; sus ojos estaban maquillados; llevaba una capa mullida y zapatos finos; pesados anillos resplandecían en sus dedos" (Chariton, 1989: 27) ${ }^{8}$. El afeminamiento ha funcionado tradicionalmente como un signo del exceso heterosexual en los varones.

Hubo hombres, evidentemente, a los que les gustaba que los hombres sean rudos y duros. A ellos les podría gustar, quizás, que sus mujeres y muchachos fueran suaves y tiernos, pero no respetaban esas características en un hombre maduro. Las mujeres, por el contrario, parecen haber encontrado más atractivo el estilo suave de masculinidad. Esto ha creado una cierta tensión entre normas de género y placer erótico en culturas tradicionalmente masculinas. La instancia paradigmática que ilustra el tradicional choque entre los estilos fuertes y suaves de masculinidad puede ser encontrada en la figura de Hércules. Hércules es un héroe que oscila entre extremos de hipermasculinidad y afeminamiento: es preternaturalmente fuerte, pero se encuentra a sí mismo esclavizado por una mujer (la Reina Ónfale); sobrepasa a todos los hombres en fuerza, sin embargo, es arrastrado a la locura por el amor, ya sea el de una mujer (IÍle) o el de un muchacho (Hilas) (Loraux, 1990). Hércules establece el guion a seguir para figuras modernas tales como el Marco Antonio de Shakespeare, quien reivindica a Hércules como su literal ancestro en Antonio y Cleopatra, y que incurre en cargos similares de afeminamiento cuando se toma un tiempo libre del gobierno del Imperio Romano para vivir una vida de pasión e indulgencia con Cleopatra. Los roles de gobernante y amante están hechos para el contraste desde el comienzo mismo de la obra, cuando Antonio es descrito como "el triple pilar del mundo transformado / en el bufón de una meretriz" (Acto I, escena 1, pp. 12-13).

Antonio no es el único en Shakespeare. Otelo también da voz a ansiedades acerca de los efectos incapacitantes del amor conyugal sobre un líder militar. Sin embargo, esta tensión está mejor representada, para nuestros propósitos, por Romeo, que quizás figura actualmente como un icono de heterosexualidad masculina, pero que alguna vez vio su propio ardor romántico bajo una luz menos normativa. Reprochándose a sí mismo por su falta de fuerza marcial; rechazando pelear con el primo de Julieta, Teobaldo; e invocando la tradicional oposición entre la melancolía fría y humedad del amor y la naturaleza caliente y seca de la virtud masculina, Romeo exclama: "Oh, dulce Julieta / tu belleza me vuelve afeminado / ¡Se ablanda en mí el acero del valor!"9.

${ }^{8}$ De manera similar, Artemidoro observa que los hombres que sueñan que llevan maquillaje facial, joyas o ungüentos, sufrirán desgracia (es decir, serán expuestos) como adúlteros. Ver al respecto el trabajo de MacAlister (1992). Comparar, además, con las representaciones de Agatón en la comedia antigua (Zeitlin, 1996; Muecke, 1982).

${ }^{9}$ Ver Orgel (1996: 25-26). Quiero agradecer a Vernon Rosario por sugerirme el lustre humoral de este pasaje. Ver también Cady (1996), especialmente 132-133: "Sin embargo, en el Renacimiento, la palabra 'afeminado', cuando se aplicaba a un varón, no connotaba automáticamente homosexualidad, sino que tenía, en su lugar, una diversidad de significados que falta en la actualidad. Por ejemplo, el término a veces designaba una heterosexualidad masculina hiperactiva o incapaz, un 
La supervivencia e interacción de estas diferentes nociones de afeminamiento ayudarían a explicar la persistente ambigüedad sexual que se atribuye, incluso hoy, a las instituciones predominantemente masculinas, tales como las fraternidades, las fuerzas armadas, la iglesia, las salas de directorio o el congreso: ¿se debe considerar la clase de hombría fomentada y expresada ahí como la más verdadera y más esencial forma de masculinidad, virilidad en su más alta y pura forma, o una excepcional y bizarra perversión de la misma?

En síntesis, el afeminamiento necesita ser diferenciado de la homosexualidad. Esto me lleva a la segunda categoría homosexual que quiero describir: pederastia o sodomía "activa". Estos términos, como voy a usarlos, se refieren a la penetración sexual, por parte de un hombre, de un subordinado masculino, subordinado en términos de edad, clase social, estilo de género y/o rol sexual ${ }^{10}$. Tal noción de subordinación refleja la simbolización social más extendida de penetración fálica como un ejercicio de poder jerárquico. De acuerdo con esto, los discursos de pederastia o sodomía activa se forman a partir de una distinción crucial entre el deseo masculino de penetrar y el deseo masculino de ser penetrado $y$, en consecuencia, entre pederastia o sodomía activa, en un lado de la ecuación jerárquica, y pasividad masculina o inversión, en el otro. Mi diferenciación entre la segunda y la cuarta de las cinco categorías se ajusta a esta distinción.

Los sexólogos del siglo XIX, que heredaron esta tradicional oposición y que la elaboraron sistematicamente en la distinción entre pederastia ("amor griego") y pasividad ("sentimiento sexual contrario" o "inversión del instinto sexual"), basaron su división en una distinción psiquiátrica entre "perversidad" y "perversión", de acuerdo con la cual una orientación sexual invertida, transgenérica o pasiva

uso que, por supuesto, no existe más. La declaración de Donne de que es llamado 'afeminado' porque 'ama las joyas de las mujeres', en su epigrama 'El Juglar' (¿1587?-¿1596?), pertenece a esta tradición del Renacimiento". Para mayores detalles Cady remite al lector a un ensayo previo, "Renaissance Awareness and Language for Heterosexuality: 'Love' and 'Feminine Love'" (1993).

${ }^{10}$ Los sistemas culturales individuales de jerarquía social y sexual tienden a colapsar las distinciones entre estas diferentes categorías u órdenes de subordinación, tratando a los muchachos como femeninos, o a las mujeres como menores, a lxs compañerxs sexuales pasivxs (de cualquier sexo) como femeninxs, o a los compañerxs feminizadxs como menores: por esta razón, Alan Sinfield habla de "una combinación de subordinaciones", y destaca el elemento de poder desigual que consistentemente estructura la vida erótica, señalando que "las elaboradas estructuras sociales de la modernidad ofrecen jerarquías igualmente potentes de clase y raza, que también se pueden fusionar con subordinaciones de edad y género" (Sinfield, 1998: 66). Ver también, de Sinfield, el artículo "The Production of Gay and the Return of Power" (2000). Sinfield desarrolla más en profundidad el argumento en "Lesbian and Gay Taxonomies" (2002). Mientras que estoy de acuerdo con el énfasis político que pone Sinfield en su explicación del erotismo, deseo mantener las diferentes categorías u órdenes de subordinación separados, tanto analítica como empíricamente, de manera de poder describir, en cualquier situación social particular, la naturaleza exacta de la jerarquía en cuestión. No todos los sistemas de jerarquía combinan todas las subordinaciones, ni lo hacen de la misma manera. Además, en cualquier contexto social particular, se deben hacer importantes distinciones entre clases de identidades subordinadas: esto es, los muchachos pueden ser vistos como menores pero no necesariamente como femeninos; las mujeres pueden ser vistas como subordinadas pero no necesariamente como menores; lxs compañerxs sexuales pasivxs pueden ser vistxs como dominadxs pero no necesariamente como feminizadxs. Es importante preservar la posibilidad de tener en cuenta esas diferencias, que pueden figurar significativamente en las mentes de actores sociales particulares, así como también en los códigos sexuales de grupos sociales. 
siempre indicaba perversión en un hombre, mientras que la penetración sexual de un subordinado podría calificar simplemente como "perversidad". Estos escritores y médicos victorianos, que permanecerían largo tiempo indiferentes a la distinción entre homo y heterosexualidad (la cual todavía tenía que afirmar su ascendencia sobre modelos anteriores de clasificación sexual), se esforzaron en determinar si los actos sexuales desviados procedían del carácter moralmente depravado de un individuo (es decir, perversidad) -en otras palabras, si esos actos eran el mero resultado del vicio, y podrían ser refrenados con leyes y castigados como un delito- o si se originaban en una condición patológica (es decir, perversión), una enfermedad mental, una "sexualidad" pervertida, que solo podría ser tratada médicamente.

La distinción es expuesta por Krafft-Ebing (citado en Davidson, 1990: 315) como sigue: "Perversión del instinto sexual... no debe ser confundida con perversidad en el acto sexual; dado que la última puede ser inducida por condiciones que no son psicopatológicas. El acto perverso concreto, tan monstruoso como pueda llegar a ser, no es clínicamente decisivo. Con el fin de diferenciar entre enfermedad (perversión) y vicio (perversidad), se debe investigar la personalidad completa del individuo y el motivo original que lo llevó al acto perverso. En ello se encontrará la clave para el diagnóstico". La penetración sexual masculina de un subordinado masculino representa ciertamente un acto perverso, pero no significaría en todos los casos una perversión del instinto sexual, una enfermedad mental que afecte "la personalidad completa": indicaría un carácter moralmente vicioso más que una condición patológica.

Implícita en esta doctrina, y altamente significativa para los propósitos de mi análisis, es la premisa de que no había nada necesariamente anormal sexual o psicológicamente en sí mismo en la penetración sexual, por parte de un varón, de un subordinado masculino. El hombre que desempeñaba un rol "activo" en el intercambio sexual con otros hombres era convencionalmente masculino, tanto en la presencia como en sus modos de actuar y sentir; si no buscaba ser penetrado por otros hombres, y/o tenía además relaciones sexuales con mujeres, no sería un enfermo sino un inmoral, no sería un pervertido sino sencillamente un perverso. Su penetración de un subordinado masculino, aunque reprensible y abominable, podía considerarse como una manifestación de su excesivo, pero por otro lado normal, apetito sexual masculino. Al igual que la figura un poco anterior, aristocrática, del "libertino", tal hombre rechazaría perversamente limitar sus opciones sexuales a los placeres supuestamente prescritos por la naturaleza, y en su lugar buscaría otros, más inusuales, fuera de la ley, sofisticados, o experiencias sexuales elaboradas para gratificar sus hastiados gustos sexuales ${ }^{11}$. En el caso de estos hombres, la pederastia o sodomía era signo de un carácter inmoral, pero no de un desorden de la personalidad, de "insanidad moral" o de anormalidad psicológica ${ }^{12}$.

Las distinciones de los sexólogos entre lo perverso y lo pervertido, entre lo inmoral y lo patológico, entre lo meramente vicioso y lo enfermo, puede sonar para nosotros como pintorescamente victo-

11 Sobre los tipos aristocráticos mencionados, ver Trumbach (1989).

12 Sigo aquí los argumentos de Davidson (1990) y Chauncey (1989). 
riano, pero prominentes psicólogos, sociólogos y juristas continúan realizando, todavía hoy, distinciones similares entre "pseudo-homosexualidad" y "homosexualidad" o entre homosexualidad "situacional", "oportunista", y lo que ellos llaman, a falta de un mejor término, homosexualidad "real" ${ }^{13}$. Los actos de penetración homosexual realizados en prisión por hombres que llevan vidas heterosexuales fuera de la prisión, por ejemplo, son considerados a menudo no como síntomas de una orientación psicosexual particular, o como expresiones de deseo erótico, o incluso como "homosexualidad", sino como meras adaptaciones conductuales a una sociedad sin mujeres. Tal comportamiento, a menudo se cree todavía hoy, responde simplemente a la capacidad masculina de disfrutar formas variadas de gratificación perversa ${ }^{14} y$, además, de erotizar jerarquías: excitarse sexualmente con la oportunidad de jugar un rol dominante en relaciones estructuradas de poder desigual.

De hecho, la distinción entre una homosexualidad casi-normal, no homosexual, y una inversión sexual absolutamente desviada -la distinción que fue sistemáticamente elaborada en la psiquiatría del siglo XIX y que pervive todavía hoy- no se originó en el periodo victoriano. Refleja una práctica antigua de clasificación de relaciones sexuales en términos de penetrar versus ser penetrado, estatus superior versus estatus subordinado, masculinidad versus feminidad y actividad versus pasividad, es decir, en términos de jerarquía y género, más que en términos de sexo y sexualidad. Posible evidencia de un patrón jerárquico de relaciones sexuales, estructurado por edad y rol específico, puede hallarse en la cuenca mediterránea tan pronto como en las civilizaciones de la Creta minoica de la Edad de Bronce en el final del segundo milenio a. C., y tan tarde como en las ciudades renacentistas italianas de los siglos 14 y 15 d. $\mathrm{C}^{15}$. Las más conocidas y completamente documentadas instancias históricas de este patrón son probablemente la pederastia de las antiguas Grecia y Roma y la sodomía de la Europa Medieval, pero el patrón mismo parece preexistirlas y sobrevivirlas ${ }^{16}$.

La evidencia procedente de los archivos judiciales de la Florencia del siglo XV es lo suficientemente detallada para permitirnos entrever el alcance y la distribución de la actividad sodomítica en una

${ }^{13}$ Ver, para algunos ejemplos recientes, Vanggaard (1972: 17 et passim), Ovesey (1969) y Posner (1992, esp. 105-107, 152 y 296).

Para una genealogía de esta distinción entre homosexualidad situacional y homosexualidad verdadera, ver el penetrante análisis de Kunzel (2002), quien subraya también las continuidades entre la así llamada homosexualidad situacional y formaciones sexuales anteriores, tales como pederastia/sodomía e inversión (mis términos, no los de la autora).

${ }^{14}$ Ver, por ejemplo, Dowsett (1996).

15 Para la Edad de Bronce de Creta, ver Koehl (1986 y 1997).

16 Para algunos ejemplos modernos, ver Chauncey (1985/1986), Marshall (1981, esp. 149-152), Reiss (1961/1962) y Gagnon y Simon (1973: 240-251). Alan Sinfield (2002) manifiesta que "el modelo de la edad" de relaciones homosexuales todavía florece en las culturas occidentales posindustriales en la actualidad y, de hecho, "figura en muchos de los más influyentes libros de nuestro tiempo", como en La biblioteca de la piscina [The Swimming-Pool Library] (1989) de Alan Hollinghurst o Listo para sostenerlo si se cae [Ready to Catch Him Should He Fall] (1991) de Neil Bartlett (Nota de los editores: ambos traducidos al español). De manera similar, Stephen Murray (2000: 12) sostiene que "las relaciones pederásticas continúan existiendo incluso hoy en ciudades con generalmente conocidos barrios e instituciones gais". Pero el patrón que estoy describiendo aquí no se define simplemente por una diferencia de edad o en generación entre dos compañeros masculinos, sino por (entre otras cosas), un patrón en gran medida asimétrico o no recíproco de deseo y placer, que es un elemento difícilmente prominente en las dos novelas citadas por Sinfield o, me atrevo a pensar, en las relaciones contemporáneas a las que se refiere Murray. "Pederastia/sodomía" es un patrón mucho más específico de que lo que Sinfield entiende por "el modelo de la edad", que para él es, en realidad, una subcategoría de la homosexualidad. 
(ciertamente notoria) comunidad europea premoderna. Entre 1432 y 1502 tantos como 117.000 individuos en Florencia, la mayoría de ellos varones, fueron formalmente incriminados, al menos una vez, por sodomía, sobre un total de población de 40.000 hombres, mujeres y niños: dos de cada tres hombres que alcanzaron la edad de 40 en este periodo fueron formalmente incriminados por sodomía. Entre quienes fueron imputados, aproximadamente el $90 \%$ de los compañeros pasivos (incluyendo, de acuerdo con las nociones florentinas, los compañeros insertivos en la cópula oral, así como los compañeros receptivos en el intercambio anal) tenían 18 años o menos, y el 93\% de los compañeros activos tenían 19 o más, la gran mayoría en la edad de 30 a 35, la época de la vida en que los hombres, por regla general, se casaban ${ }^{17}$.

Esto es sexo como jerarquía, no mutualidad; sexo como algo hecho a alguien por alguien más, no una búsqueda común de un placer compartido o una experiencia puramente privada, personal, en el que identidades sociales más amplias, basadas en la edad o el estatus social, se sumergen o se pierden. Aquí el sexo implica diferencia, no identidad, y se convierte en una división sistemática del trabajo. Es el compañero más joven el que se considera sexualmente atractivo, mientras que el mayor es el que experimenta deseo erótico por el más joven. Aunque el amor, la intimidad emocional y la ternura no están necesariamente ausentes de la relación, la distribución de pasión erótica y placer sexual se asume como más o menos asimétrica, con el compañero mayor, "activo", siendo el sujeto de deseo y quien recibe la mayor cantidad de placer de un compañero más joven, que figura como objeto sexual, que siente un placer no comparable y deriva un placer no comparable del contacto (al menos que sea un invertido $y$, en consecuencia, pertenezca a mi cuarta categoría). La recompensa del compañero más joven debe ser medida entonces materialmente más que en placer: elogios, ayudas, regalos, dinero. Como experiencia erótica, experiencia de pasión o deseo, la pederastia o sodomía se refiere solo al compañero activo ${ }^{18}$.

Este modelo tradicional, jerárquico, de relaciones sexuales masculinas, representa la preferencia sexual sin orientación sexual (en el caso del compañero activo, que es todavía el punto de referencia aquí). Numerosos textos que se remontan a la Antigüedad Clásica dan cuenta de una preferencia erótica consciente, por parte de hombres, incluso hasta el punto de la exclusividad en el intercambio sexual, por miembros del propio sexo más que del contrario; más aún, un venerable subgénero de la literatura erótica consiste en debates formales entre dos "hombres" sobre si las mujeres o los muchachos son vehículos superiores de gratificación sexual masculina ${ }^{19}$. (Con "hombres" me refiero a varones adultos, socialmente empoderados, como puestos a jóvenes o "muchachos" subordinados). Estos debates lúdicos están ampliamente extendidos en las literaturas de ocio de las sociedades masculinas tradicionales: se pueden encontrar ejemplos en la prosa griega de la última Antigüedad,

\footnotetext{
17 Ver Rocke (1996), cuyas estadísticas, sin embargo, han sido objeto de críticas, por ejemplo, por parte de Cohen (1999).

${ }^{18}$ Así, por ejemplo, las definiciones florentinas de "sodomía" y "sodomita" de los siglos XVI y XV hacen referencia únicamente al compañero "activo" o insertivo en el intercambio anal (Rocke, 1996: 14 y 119).

${ }^{19}$ Ver Halperin (1990: 163, n53) para una lista reconocidamente incompleta de textos antiguos griegos y romanos que documentan una preferencia erótica consciente de parte del hombre por intercambios sexuales con miembros del propio sexo más que del opuesto.
} 
en poesía y prosa medieval europea y arábiga, en escritos chinos del último periodo imperial, y en literatura japonesa del siglo XVIII20.

Sin embargo, las explícitas y conscientes preferencias eróticas expresadas en estos contextos no deberían ser equiparadas con declaraciones de orientación sexual por al menos tres razones. En primer lugar, se presentan como el resultado de una opción consciente, una opción que expresa los valores del sujeto masculino y un modo de vida preferidos, más que como síntomas de una condición psicosexual involuntaria. Los hombres que expresan tales preferencias a menudo se ven a sí mismos, al menos nominalmente, como capaces de responder al atractivo erótico tanto de hombres como de mujeres. Esto es una elección de objeto sexual como expresión de ética o estética, como un ejercicio de experticia erótica, no como un reflejo de sexualidad. Se parece más al vegetarianismo que a la homosexualidad. En segundo lugar, la elección de un objeto sexual del mismo sexo, en y por sí misma, no funciona necesariamente en este contexto como un marcador de diferencia. No individualiza a los hombres en términos de su sexualidad. Por último, la elección de un objeto sexual del mismo sexo, en este caso, no se marca a sí misma visiblemente en la apariencia física de un hombre, ni se inscribe a sí misma en sus modales o comportamiento personales. Tampoco impugna su masculinidad ${ }^{21}$.

Sin embargo, la pederastia o sodomía provee una oportunidad y un contexto para que los hombres expresen y discutan sus gustos sexuales, para que exploren sus subjetividades eróticas y para que comparen sus preferencias sexuales. Es en el contexto de reflexión erótica por parte de varones masculinos convencionalmente superiores, empoderados, que los hombres han sido capaces de articular preferencias eróticas conscientes, a veces hasta el punto de la exclusividad, por relaciones sexuales con muchachos o mujeres, así como por relaciones sexuales con cierta clase de muchachos o mujeres. La altamente elaborada, ritual, conspicuamente pública práctica del cortejo o galanteo, provee socialmente, a hombres socialmente empoderados, de un espacio discursivo tradicional, socialmente sancionado, para que articulen tales preferencias y se presenten a sí mismos como objetos conscientes de deseo.

Este es un punto importante para los historiadores y ha sido oscurecido durante mucho tiempo. John Boswell, quien definió influyentemente como "sexualidad gay" todo erotismo del mismo sexo asociado "con una preferencia consciente", pensó que si encontrara evidencia, en la Europa premoderna, de preferencias eróticas conscientes de unos hombres por otros, habría documentado la existencia de "sexualidad gay" en ese periodo también (Boswell, 1980: 44). Por supuesto, la evidencia de preferencias eróticas conscientes existe en abundancia a través de los archivos documentales que han sobrevivido, pero tienden a ser encontrados en el contexto de discursos vinculados con los compa-

${ }^{20}$ Para referencias más detalladas, ver Halperin (2002: 180-181, n20 y 21); también Rowson (1991) y Wright y Rowson (1997).

${ }^{21}$ Ver Herrup (1999: 33): "Los procesos por sodomía sobre los cuales tenemos información antes del siglo XVII raramente condenaban a los acusados por comportamiento afeminado; del mismo modo, las reprobaciones por afeminamiento raramente incluían ejemplos sexuales". 
ñeros superiores en las relaciones jerárquicas de pederastia o sodomía. Esto, en consecuencia, señala la existencia no de sexualidad gay, sino de un discurso particular y un conjunto de prácticas que constituyen un aspecto de lo que cuenta como sexualidad gay en nuestros días, un aspecto de la sexualidad gay que un hombre no gay podría identificar con la totalidad de la sexualidad gay. Las declaraciones de preferencias eróticas conscientes se encuentran raramente, si se encuentran, en el contexto de los otros tres discursos tradicionales de erotismo masculino y desviación de género entre personas del mismo sexo discutidas aquí. Y entonces, las preferencias conscientes por personas del mismo sexo no deberían ser equiparadas con la totalidad de la sexualidad gay o la homosexualidad masculina. Representa meramente una tradición histórica entre muchas otras ${ }^{22}$.

Muy alejado del mundo jerárquico de la penetración sexual de varones subordinados por varones superiores, es el mundo del amor y la amistad masculinas, que posee, igualmente, una antigua tradición discursiva. Sin dudas, la jerarquía no está siempre ausente de la relaciones sociales entre amigos varones: desde la camaradería heroica de Gilgamesh y Enkidu en la babilónica Épica de Gilgamesh, David y Jonatán en los libros bíblicos de Samuel, Aquiles y Patroclo en La Ilíada, a las exhibiciones públicas de afección real por el rey inglés Jaime I y sus cortesanos varones, hasta los últimos thrillers bi-raciales de policías americanos, las amistades masculinas revelan a menudo llamativos patrones de asimetría ${ }^{23}$. Precisamente en la medida, sin embargo, en que tales amistades están estructuradas por divisiones sociales o por desigualdades de poder; en la medida en que se aproximan a relaciones patrón-cliente en las que los dos amigos son asignados con roles, tareas y posturas radicalmente diferentes; es solo en esa medida que tales amistades se abren a la posibilidad de ser interpretadas, entonces como ahora, en términos pederásticos o sodomíticos ${ }^{24}$. Dentro de los horizontes del mundo masculino, como podemos ver, la jerarquía es en sí misma excitante: está indisolublemente ligada con al menos el potencial para la significación erótica. Por consiguiente, las disparidades de poder entre íntimos masculinos toma inmediata e inescapablemente un aura de erotismo. A la inversa, lo que a menudo nos parece a nosotros actualmente erotismo, podría haber servido en el pasado para constituir, para dramatizar y para identificar como "amistades" relaciones rutinarias de dependencia entre personas desiguales ${ }^{25}$.

22 Para un intento por documentar numerosos ejemplos de elección de objeto del mismo sexo, e incluso de preferencias eróticas conscientes por personas del mismo sexo de unx, pero que sin embargo no satisfacen los criterios de homosexualidad, ver Halperin (2002: 81-203).

23 Para más información sobre Jaime y sus cortesanos varones, ver Bray y Rey (1999). Para una mirada general sobre los patrones de asimetría en amistades masculinas, ver Halperin (1990: 75-87 y 176-179).

${ }^{24}$ Ver Bray (1994). Interpreto que Bray proporciona evidencia para su afirmación, aunque no termina de formularla del todo. Ver también Herrup (1999: 33): "Sean o no realmente pederásticas, las relaciones sodomíticas descritas en los archivos legales vinculan autoridad y dependencia -hombres y muchachos, jefes y sirvientes, profesores y pupilos, patrones y clientes".

${ }^{25}$ Alan Sinfield (2000: 27) enfatiza lo que él parece considerar la sensualidad [sexiness] intrínseca del poder (como opuesta a su sensualidad contingente dentro de contextos históricos y culturales específicos, como preferiría yo). Por contraste, Bray y Rey (1999), enfatizan bastante adecuadamente que las amistades virtuosas entre hombres de rangos desiguales eran mundos aparte de lo que contaba como "sodomía" en Inglaterra antes del siglo XVII. 
No sorprende, entonces, que tres y cuatro centurias después de la composición de La llíada, algunos griegos del periodo clásico interpretaran a Aquiles y Patroclo como pareja pederástica (aunque no siempre se pusieran de acuerdo en quién era el hombre y quién el muchacho), mientras que más recientemente algunos investigadores han discutido si Jaime I fue homosexual o si David y Jonatán fueron amantes. Tales disputas, que a menudo tienen una larga historia, tienden a fusionar nociones de amistad primero con nociones de jerarquía erótica, pederastia o sodomía y luego con nociones de homosexualidad. Sería útil, en consecuencia, distinguir amistad tanto de jerarquía erótica como de deseo homoerótico.

Debería ser destacado que, además de la tradición del guerrero heroico con su subordinado colega masculino o camarada (que inevitablemente muere), además del modelo patrón-cliente de amistad masculina que podría haber sido de modelo dominante de amistad en el primer periodo moderno, hay otra tradición que enfatiza la igualdad, la mutualidad y la reciprocidad en el amor entre varones ${ }^{26}$. Tal relación igualitaria puede obtenerse solo entre dos hombres que ocupan el mismo rango social, usualmente una élite, y que pueden declarar el mismo estatus en términos de edad, masculinidad y empoderamiento social. En los libros 8 y 9 de su Ética a Nicodemo, Aristóteles defiende precisamente tal modelo de amistad recíproca entre dos varones iguales, y escribe, de manera más influyente, que la mejor clase de amigo es un "otro de sí mismo", un allas autos o alter ego. La opinión es repetida en numerosas ocasiones a lo largo de centurias: un verdadero amigo es una parte de uno mismo, indistinguible de uno mismo. Los verdaderos amigos tienen una sola mente, un solo corazón en dos cuerpos. Como Montaigne escribe en su ensayo "Sobre la amistad", "Nuestras almas se mezclan y fusionan una con otra tan completamente que difuminan la costura que las unió, y no se puede encontrarla nuevamente" (Montaigne, 1958: 139). La amistad entre hombres virtuosos se caracteriza por un amor desinteresado que conduce a una función de identidades individuales $y$, por consiguiente, a una negativa a vivir sin el otro, una disposición a morir con o por el otro. Encontramos el tema de la inseparabilidad de amigos masculinos tanto en la vida como en la muerte repetidamente, una y otra vez, desde las representaciones de Aquiles y Patroclo, Orestes y Pílades, Teseo y Pirítoo en el mundo antiguo, hasta las de Mel Gibson y Danny Glover en Arma Mortal en el mundo moderno.

El lenguaje usado para verbalizar tales uniones apasionadas masculinas a menudo se parece a las sensibilidades modernas sospechosamente "caliente", cuando no rotundamente erótico. Así, Montaigne puede escribir:

Si me presionas para que te diga por qué lo amé, siento que esto no puede ser expresado, excepto respondiendo: porque era él y porque era yo. No sé qué fue... que, habiéndose apoderado de mi entera voluntad, la llevó a sumergirse y perderse en la suya; que, habiéndose apoderado de su entera voluntad, la llevó a sumergirse y perderse en la mía, con idéntica ansia, con idéntica rivalidad. [Nótese que la

\footnotetext{
${ }^{26}$ Ver, nuevamente, Bray y Rey (1999), para una breve pero panorámica valoración del modelo de amistad cliente-patrón en Inglaterra desde la Edad Media hasta finales del siglo XVII.
} 
insistencia de Montaigne en la perfecta igualdad en la amistad está enfatizada incluso en el nivel sintáctico de su prosa, por el paralelismo y la mutua correspondencia de las cláusulas que remiten a devoción recíproca de los dos amigos]. No había nada suyo o mío. Nuestras almas se juntaron en una unión tal, se contemplaban con una afección tan ardiente, y con una afección tal se revelaban la una a la otra hasta las profundidades de nuestros corazones, que no solo conocí tu alma tan bien como la mía, sino que me hubiera confiado a él más fácilmente que a mí mismo. (Montaigne, 1958: 139-140)

De manera similar, en un drama de tema romano de Dryden de 1677, All for Love, Antony puede decir sobre su noble amigo Dolabella:

Yo era su alma, él no vivía sino en mí.

Éramos tan cercanos dentro del pecho del otro,

Que no se encontraban los remaches que nos había unido en el comienzo.

[Comparar con Montaigne: "Nuestras almas se mezclan y fusionan una con otra tan completamente que difuminan la costura que las unió, y no se puede encontrarla nuevamente"].

Que no nos alcanza todavía; estábamos tan mezclados

Como arroyos confundidos, ambos para nosotros mismos perdidos;

Éramos una única masa; no podíamos dar o tomar

Sino de lo mismo; porque él era yo, y yo él ${ }^{27}$.

Es difícil para nosotros, modernos - con nuestro modelo altamente psicologista de la personalidad humana, nuestra noción de las fuerzas inconscientes, nuestra tendencia a asociar deseo con sexualidad y nuestra sensibilidad extrema hacia todo lo que parecería contravenir los estrictos protocolos de masculinidad heterosexual- es difícil para nosotros evitar leer en tales expresiones apasionadas de amor masculino un indicio de "homoerotismo" como mínimo, cuando no de "homosexualidad latente", siendo estas las formulaciones que a menudo actúan como un pretexto para nuestra propia perplejidad sobre cómo interpretar las emociones entre personas del mismo sexo que no cuadran lo bastante con las concepciones canónicas de subjetividad sexual. Pero además de la dificultad de entrar en las vidas emocionales de sujetos premodernos, necesitamos considerar los contextos discursivos en los cuales tales declaraciones apasionadas fueron producidas.

27 Debo esta cita a Haggerty (1999: 25), quien la interpreta elocuentemente pero casi en el sentido contrario al mío. Para una aproximación diferente a este tópico, ver Jaeger (1999). 
La insistencia temática de algunos textos en la mutualidad y la fusión de identidades individuales, aunque pueda invocar en nuestra mente de lectores modernos las fórmulas del amor heterosexual romántico, de hecho sitúa las declaraciones de amor recíproco entre amigos masculinos, en una tradición honorable, incluso glamorosa, de camaradería heroica: precisamente removiendo cualquier rastro de subordinación de parte de un amigo hacia otro $y$, en consecuencia, cualquier indicio de jerarquía, el énfasis en la fusión de dos almas en una, en realidad, distancia tal amor de la pasión erótica. Montaigne incluso expresa desesperación acerca de la imposibilidad de combinar los dos tipos de emoción dentro de los confines de una única relación ${ }^{28}$. Él ciertamente no revela la más mínima duda, al escribir sobre su amor por Etienne de La Boétie, de que los sentimientos que expresa son enteramente normativos, incluso admirables y dignos de alarde (aunque por supuesto únicos en su especificidad). Lejos de ofrecernos claves acerca de su psicopatología, revelarnos inadvertidamente rastros de sus deseos suprimidos o inconscientes, o de expresar sus peculiaridades eróticas (cosa que hace libremente en otros momentos de sus Ensayos), Montaigne deliberadamente inmuniza su relato de esa amistad de una interpretación poco respetable, presentando de forma muy elaborada su amor como igualitario, no jerárquico y recíproco. Por esos medios, lo arranca de los dominios eróticos de la diferencia y la jerarquía, ubicándolo de forma explícita contra el amor sexual de los hombres y las mujeres, por un lado, y contra el disfrute sexual masculino de los muchachos por el otro.

Esto no quiere decir que los amantes masculinos no se pudieran sentir atraídos por la tradición de la amistad como una forma de cubrir, o al menos como un medio para ennoblecer, la pasión erótica: “¿Por qué deberías arrodillarte?”, pregunta Eduardo II a Gaveston en la recreación de Marlowe de la historia; "¿sabes quién soy yo? / ¡Tu amigo, tu ser, otro Gaveston!" (El Antony de Dryden podría estar evocando este mismo precedente). Pero esto indica que el amor sexual, al menos como es visto dentro de los horizontes culturales del mundo masculino, concierne sobre todo a la penetración y, en consecuencia, es sobre todo una cuestión de posición, superioridad e inferioridad, rango y estatus, género y diferencia. La amistad, por contraste, concierne sobre todo a la igualdad: igualdad de rango y estatus, igualdad de sentimiento, igualdad de identidad. Es su mismo énfasis en la identidad, similitud y mutualidad lo que distancia la tradición de la amistad en su contexto original, social y discursivo, del mundo del amor sexual. El amor sexual, en la luz de la tradición de la amistad masculina, en realidad suena como una contradicción en sus términos: la penetración sexual no es la clase de cosa que harías a alguien a quien realmente amas.

De modo que, si la tradición de la amistad masculina mantiene una cierta distancia del mundo de la diferencia sexual y de las relaciones sexuales, ¿por qué incluir un reporte de esta tradición aquí, en una genealogía de homosexualidad masculina? Porque la tradición de la amistad dotaba a los hombres socialmente empoderados con un espacio discursivo establecido, en el cual expresar, sin reproche social, sentimientos de amor mutuo y apasionado por el otro. Y tal amor mutuo, apasionado, entre personas del mismo sexo, es un importante componente de lo que ahora nosotros llama-

${ }^{28}$ Ver Schachter (2001) para un estudio detallado de esta tensión en Montaigne. 
mos homosexualidad. Si es que vamos a trazar una completa y satisfactoria genealogía de la homosexualidad masculina, tendremos que encontrar un lugar en ella para la historia del amor masculino.

Tanto pederastia/sodomía como amistad/amor están en consonancia con las normas del género masculino, con la masculinidad convencional tal como ha sido definida en un gran número de culturas europeas. La pederastia y la amistad son tradicionalmente masculinizantes, en la medida en que expresan la virilidad del sujeto masculino e implican un rechazo completo de todo lo femenino. Ambas, en consecuencia, pueden ser vistas como reforzadoras de la identidad de género masculino (aunque no, por supuesto, en cada instancia). Como tales, pertenecen a un diferente universo conceptual, moral y social de lo que los griegos Ilamaban kinaidia, los romanos mollitia y los sexólogos del siglo XIX "sentimiento sexual contrario" o "inversión sexual". Todos estos términos se refieren a la "inversión" masculina o a la reversión de la identidad de género masculina, una completa rendición de la masculinidad en favor de la feminidad, una condición transgenérica expresada en todo, desde el comportamiento y estilo personales, a la apariencia física, la manera de sentir, la atracción sexual hacia hombres "normales" y la preferencia de un rol "pasivo" o receptivo en el intercambio sexual con tales hombres.

El mero hecho de ser sexualmente penetrado por un hombre es mucho menos significativo para la clasificación sexual de los pasivos o invertidos que la cuestión del placer del varón penetrado. En los sistemas europeos premodernos de pederastia y sodomía los muchachos podían ser sexualmente penetrados, pero no se supone que derivaran demasiado placer de este acto; ellos eran más o menos objetos dispuestos del deseo adulto masculino, no se les asignaba una porción de deseo igual a la de sus compañeros masculinos mayores, ni se esperaba que disfrutaran siendo penetrados por ellos. Aunque eran pasivos en términos de su comportamiento, no eran "pasivos" en su temperamento erótico o actitud en general: no se excitaban por la promesa o el acto de sumisión. Tenían que estar motivados para someterse a sus amantes masculinos por una variedad de alicientes en su gran mayoría no sexuales, tales como regalos o amenazas. La "pasividad" no se extendía, entonces, a su deseo, que permanecía no comprometido y podía, en consecuencia, declararse incontaminado por cualquier impulso hacia la subordinación o cualquier indicio de "feminidad". En este sentido, sostenían y encarnaban, incluso mientras jugaban el rol sexual "pasivo", estándares tradicionales de virilidad.

Los kinaidoi (cinaedi en latín) e invertidos, por el contrario, deseaban activamente someter su cuerpo "pasivamente" a la penetración sexual por hombres, y en este sentido eran vistos como poseedores del deseo, la subjetividad y la identidad de género de una mujer. La categoría de invertido o pasivo masculino se aplicaba especialmente a hombres subordinados cuya disposición a someterse a sí mismos a la penetración sexual por hombres procedía no de algún motivo no sexual (incluyendo amor por su compañero) sino de sus propios deseos eróticos y/o de su asunción de una identidad de género femenina. 
Aunque el placer que obtenía al ser sexualmente penetrado podía ser la más flagrante, la más extrema expresión de la total reversión de género que caracteriza al invertido masculino, la inversión no está necesariamente, o incluso principalmente, definida por el disfrute de actos sexuales particulares. Tampoco tiene que ver estrictamente con el deseo homosexual, porque los invertidos pueden tener sexo fálico insertivo con mujeres sin dejar de ser considerados invertidos. Más bien, la inversión tiene que ver con una identidad de género, una sensibilidad y un estilo personal desviados, uno de cuyos aspectos es el gusto femenino por un rol "pasivo" en el intercambio sexual con otros hombres. En consecuencia, las nociones de inversión no tienden a hacer una separación estricta entre manifestaciones específicamente sexuales de inversión y otras desviaciones igualmente contundentes de las normas de la masculinidad, tales como la adopción de ropas femeninas. El énfasis recae en una violación de los protocolos de la hombría, una falla caracterológica de grandes proporciones que no puede ser redimida (como sí puede serlo la sodomía) por el disfrute de relaciones sexuales con mujeres. La inversión no tiene que ver con la sexualidad sino con el género, hasta el punto de que tiene sentido separar una de otro $^{29}$.

Una manera de describir la diferencia entre afeminados y pasivos es contrastar una versión universalizante de desviación de género con otra minorizante. La "suavidad" [softness] puede representar tanto el fantasma de una falla potencial de género que persigue a la masculinidad normativa en su totalidad; una siempre-presente amenaza a la masculinidad de cada hombre; o bien, puede representar la deformante peculiaridad de una pequeña clase de individuos desviados ${ }^{30}$. Los afeminados pertenecen a la primera categoría, son hombres que sucumben a una tendencia que todos los hombres normales tienen y contra la que tienen que luchar o suprimir en sí mismos; mientras que los pasivos son hombres tan inadecuados para la lucha que pueden ser vistos como víctimas de un defecto constitucional específico, es decir, una falta de la capacidad masculina para resistir la atracción del placer (específicamente el placer obtenido considerado vergonzoso o denigrante) así como una tendencia a adoptar una actitud específicamente femenina o someterse en las relaciones con otros hombres. Los pasivos, en consecuencia, pertenecen a una categoría minorizante de desviación del género masculino.

Son estas últimas características las que definen al invertido, incluso más que su deseo o su elección de objeto sexual, porque ni su deseo ni su elección de objeto sexual son exclusivamente suyos. El deseo por un compañero masculino, por ejemplo, es algo que el invertido tiene en común tanto con el pederasta como con el amigo masculino heroico, figuras enormemente alejadas de su estatus social y moral. Del mismo modo, el deseo de ser penetrado por otro hombre es algo que el invertido tiene en común con el homosexual masculino, aunque muchos hombres gais a quienes les gusta ser penetrados no necesariamente califican como invertidos, ni a sus propios ojos ni a ojos de los demás.

${ }^{29}$ Exagero para enfatizar. Para una explicación más matizada y compleja de las interrelaciones entre sexualidad y género en el transgenerismo, ver Kulick (1998), y de este mismo autor, el artículo "Problematic Childhood Sexuality", presentado en el encuentro anual de la American Anthropological Association, Filadelfia, 2-6 de diciembre de 1999.

${ }^{30}$ Ver Sedgwick (1990: 85-86), de donde derivo la distinción entre construcciones "minorizantes" y "universalizantes" de la identidad sexual. 
La inversión también difiere de la pederastia y de la amistad en que el amor por los muchachos y el amor de los amigos no son necesariamente sentimientos desacreditados y ellos bien pueden ser confesados o incluso defendidos por los mismos sujetos. La inversión, por el contrario, es una condición vergonzosa nunca proclamada sobre uno mismo (hasta hace relativamente poco tiempo, esto es, cuando cierta desvergüenza camp ha devenido posible para algunos hombres) y casi siempre atribuida a otra persona por un acusador cuyo intento es rebajar y vilipendiar.

Además, las representaciones tradicionales de los pederastas "activos" o sodomitas no necesariamente los retratan como visiblemente diferentes, en su apariencia, de los hombres normales. No siempre se puede reconocer a un pederasta o a un sodomita observándolo. Un invertido, por el contrario, usualmente destaca, porque su inversión de la identidad de género afecta su comportamiento personal y da forma a sus actitudes, gestos y manera de conducirse en sí mismo. A diferencia de la penetración activa de muchachos, que podría diferenciar al amante de muchachos del amante de mujeres en términos de preferencia erótica, pero podría no marcarlo como una clase de persona visiblemente diferente, la pasividad o inversión sella por todas partes la presentación social de un hombre y lo identifica como un tipo social espectacularmente desviado. Es en el contexto de la inversión que podemos encontrar, a menudo, representaciones producidas y elaboradas de un tipo o estereotipo de carácter peculiar, una caricatura fóbica encarnando las características supuestamente visibles y flagrantes de la desviación masculina de sexo y género. Aunque este tipo esté vinculado al sexo homosexual, no lo está absolutamente, porque está mucho menos conectado habitualmente, o casi nunca, con la pederastia y la sodomía "activa"; más bien, parece estar asociado con el sexo homosexual pasivo o receptivo, visto como solo un aspecto de una más generalizada desviación de género, una traición subyacente de la masculinidad ${ }^{31}$. Hay un énfasis notablemente consistente, a lo largo de la historia europea de la representación sexual, sobre la morfología desviada del invertido, su modo visiblemente diferente de apariencia y vestimenta, y su autopresentación de estilo femenino. La inversión se manifiesta a sí misma exteriormente.

Esto no es desconocido para nadie. Todo el mundo parece saber cómo luce un invertido y cómo se comporta, incluso si ningún hombre normal podría, posiblemente, personificarlo. Como dice un personaje en una antigua comedia griega: "no tengo absolutamente ninguna idea de cómo usar una voz estridente o caminar en un estilo afeminado, con mi cabeza inclinada lado a lado como todos esos afectados que he visto aquí en la ciudad, embadurnados con sustancias depilatorias" (citado en Gleason, 1995: 68). De modo similar, el orador romano Quintiliano habla del "cuerpo depilado, el andar delicado, la vestimenta femenina" como "signos de que uno es blando y no un hombre de verdad" (citado por Richlin, 1993: 542). Los fisonomistas antiguos, expertos en la técnica culta de descifrar el carácter de una persona a partir de su apariencia, proveen una más detallada descripción del tipo: "podrías reconocerlo por su mirada provocativamente fija y por el rápido movimiento de sus ojos. Su frente está fruncida mientras que sus cejas y mejillas están en continuo movimiento. Su frente se inclina hacia el costado, sus lomos no se sostienen todavía y sus extremidades nunca se

${ }^{31}$ Ver Halperin (2002: 24-47), para un contraste más minucioso entre el invertido y el sodomita como tipos discursivos. 
quedan en una posición quieta. Hace palmas con las manos hacia arriba. Tiene una mirada movediza, y su voz es fina, llorosa, arrastrada"32. Todos los intentos por ocultarse resultan inútiles: "Es por el retorcimiento de sus labios y la rotación de sus ojos, por el azaroso e inconsistente desplazamiento de sus pies, por el movimiento de sus caderas y el caprichoso movimiento de sus manos, y por el temblor de su voz cuando comienzan dificultosamente a hablar, que los afeminados son más fácilmente revelados" (citado en Gleason, 1995: 78).

Pero la habilidad de desenmascarar a un invertido difícilmente se limita a los detectives especialistas en género. El líder romano Escipión Emiliano, cónsul en 147 a. C. y censor en 142, no tuvo dificultad para tildar a un oponente con todos los signos delatores: "Porque la clase de hombre que se adorna a sí mismo diariamente frente a un espejo, llevando perfume; cuyas cejas están recortadas; que deambula con la barba y los muslos depilados; que cuando era un hombre joven se reclinaba en los banquetes cerca de su amante, vistiendo una túnica larga; que es tan aficionado a los hombres como al vino: ¿puede alguien dudar de que ha hecho lo que los cinaedi tienen la costumbre de hacer?" (Aulo Gelio citado en Williams, 1999: 23) 33 . La hazaña de los cinaedi que no se puede nombrar es, por supuesto, la penetración pasiva.

Los marcadores particulares de la inversión están ligados a la cultura y, en consecuencia, son susceptibles de cambiar a lo largo del tiempo. De hecho, es en el contexto de la inversión que necesitamos estar particularmente alertas a las rupturas en la continuidad histórica, a las rupturas en las largas tradiciones de representación y conceptualización de la pasividad masculina y de la desviación de género. Desafortunadamente, un análisis de las discontinuidades dentro de estas tradiciones queda fuera del alcance del bosquejo genealógico aproximado ofrecido aquí. Llama la atención, sin embargo, la consistente legibilidad de la inversión, que permanece como una de sus características perennes. El término medieval "catamita" ["catamite"] (una palabra que, se presume a veces, sobre la base de una dudosa deducción etimológica, alude al compañero pasivo de un sodomita) es otro tipo claramente "abierto", y pertenece a la misma clase de categoría que el antiguo cinaedus mediterráneo ya descrito.

Tenemos aquí, por ejemplo, un reporte retrospectivo de los tejemanejes en la corte del rey inglés William Rufus, a finales del siglo XII, por parte de un cronista monástico llamado Orderic Vitalis: "en ese tiempo, los afeminados se pusieron de moda en muchas partes del mundo: nauseabundos catamitas, condenados al fuego eterno, perseguían sin control sus disfrutes y se entregaban vergonzosamente a la suciedad de la sodomía. Rechazaban las tradiciones de los hombres honestos, ridiculizaban el consejo de los sacerdotes y persistían en su bárbaro modo de vida y estilo de vestimenta. Peinaban su cabellera desde la parte más alta de la cabeza hacia delante, se dejaban crecer largas y

32 Este es un pasaje que reúne opiniones de escritores fisonomistas antiguos, reunidas por Gleason (1995: 63).

${ }^{33}$ Se puede valorar la distancia entre inversión o pasividad y amor masculino a partir del hecho de que Escipión estaba bastante dispuesto a identificarse públicamente a sí mismo como unido a su amigo Lelio por un "lazo de amor", de acuerdo con el historiador romano Valerio Máximo (quiero agradecer a Tom Hillard de Macquarie University por esta observación). No habría habido necesariamente inconsistencia o hipocresía en la actitud de Escipión. 
lujuriosas trenzas, como las mujeres, y amaban cubrirse con ajustadas camisas y túnicas" (citado en Olsen, 1987: 110). Nótese que nada en este pasaje establece que los "afeminados" execrados sean condenados específicamente por pasividad sexual (aunque el uso de la palabra "catamita" claramente apunta en esa dirección). Sería fácil, para un historiador incauto (o esencialista) construir la referencia a la "suciedad de la sodomía" como implicando lo opuesto -es decir, que los "afeminados" están siendo acusados también por desempeñar un rol activo en el intercambio homosexual-. Pero yo creo que es posible determinar con más precisión lo que Orderic está diciendo. Es a causa de que no hay, verdaderamente, un modo de plantear la cuestión sobre la base de un análisis puramente literario, que el acercamiento que estoy defendiendo aquí puede ayudar decisivamente en el adecuado desciframiento de textos históricos. Aunque es probable que no haya un modo de plantear el asunto de manera definitiva, sí sería posible resolver algunas ambigüedades y limitar las opciones interpretativas. En el caso de Orderic, la insistencia del texto en la desviación visible de los catamitas, su adscripción a una morfología afeminada, los sitúa en una tradición discursiva considerablemente más específica que una mera "representación masculina gay". En su lugar, el reporte parecería pertenecer a una particular tradición discursiva europea, un modo discursivo particular de representar a los invertidos masculinos o pasivos, que enfatiza su apariencia extravagantemente femenina. Cuanto más sabemos sobre las reglas y regularidades discursivas que controlan la producción de declaraciones sobre actores sexuales históricos, más fácil resulta figurarse qué está ocurriendo en un pasaje particular, incluso en ausencia de indicadores lingüísticos explícitos. En este sentido, la atención al contexto discursivo del texto de Orderic hace posible extraer de su lenguaje ambiguo e indeterminado una mejor idea de la trasgresión por la cual los "afeminados" están siendo condenados de la que podríamos tener sobre la base de sus palabras solamente.

De Orderic saltamos a través de otro intervalo en el tiempo hasta la corte renacentista del rey francés Henri III, cuando en julio de 1576 un observador, comentando indignadamente sobre los "afeminados, indecentes maquillajes y adornos" de los mignons del rey -subordinados, o queridos (un sinónimo para "catamita")- remarcó que "esos delicados mignons llevan el pelo largo, rizado y vuelto a rizar artificialmente, con pequeños bonetes de terciopelo encima, como las prostitutas de los burdeles" (citado por Cady, 1996: 133) 34 . Este es otro ejemplo de desviación masculina de género que se revela a sí misma públicamente incluso a los ojos de los hombres más apropiadamente masculinos -y que conlleva una inferencia inequívocamente sexual-.

Un siglo y medio después, los londinenses pintaron un vívido retrato de los "mollies", hombres afeminados que se reunían en forma privada en ciertas tabernas llamadas "molly houses". Samuel Stevens, cruzado religioso por la reforma de la moral, suministró una descripción en noviembre de 1725: "encontré entre 40 y 50 hombres haciendo el amor entre sí, como ellos lo llaman. Algunas veces se sentaban sobre el regazo de otro, besándose en una manera lasciva y usando sus manos indecentemente. Entonces se ponían en pie, bailaban y hacían reverencias, e imitaban las voces de

${ }^{34}$ Cady, por supuesto, llega a una conclusión diferente acerca de la existencia de la homosexualidad en el Renacimiento, a partir de este y otros comentarios de Pierre de L'Estoile. 
las mujeres. Luego se abrazaban, jugaban y se iban por parejas a otra habitación en el mismo piso para casarse, como ellos lo llamaban" (Bray, 1982: 81). Otra descripción de primera mano de una molly house incluye una descripción de un baile de disfraces realizado ahí: "Los hombres se llaman uno a otro 'mi querido' y se abrazaban, besaban y hacían cosquillas entre sí como si fueran una mezcla de hombres y mujeres disipados, y adoptaban voces y aires femeninos... Algunos estaban completamente equipados con vestidos, enaguas, tocas, finos zapatos de encaje, bufandas con faralaes y máscaras; algunos tenían capuchas; algunos estaban vestidos como mujeres lecheras, otros como pastoras con sombreros verdes, chalecos y enaguas; otros tenían las caras emparchadas y pintadas y vestían enormes enaguas de aro, que fueron introducidos bastante tarde" (87). Un eco literario de este estereotipo se puede encontrar en la figura del capitán Whiffle, en la novela Roderick Random (1748) de Tobias Smollett. Pero es un personaje de las Memorias de una mujer de placer de John Cleland (también de 1748), quien pone el énfasis tradicional en la visibilidad del invertido masculino en términos que apuntan a los discursos patologizantes de la era moderna. Hay, afirma, "un foco de infección visiblemente impreso en todos los que están contaminados" con esta pasión ${ }^{35}$.

Fue precisamente esta víctima visiblemente desfigurada de la malignidad erótica [el invertido visible] la que proveyó a los neurólogos y psiquiatras de finales del siglo XIX las bases clínicas para la primera definición y conceptualización científica sistemática de la orientación sexual patológica (o pervertida). En agosto de 1869, el mismo año que presenció la primera aparición impresa de la palabra "homosexualidad", Karl Friedrich Otto Westphal, un experto alemán en "enfermedades de los nervios" o "sistema nervioso" publicó un artículo sobre el "sentimiento" o "sensibilidad sexual contraria" [conträre Sexualempfindung], a la que presentaba como síntoma de una condición psicopática o neuropática (Westphal, 1870). Los especialistas continuaron discutiendo sobre la designación científica apropiada para esta condición, y ya por 1878 un especialista italiano llamado Arrigo Tamassia (1878) hablaría de la "inversión del instinto sexual", una designación que en última instancia probó ser más popular que la fórmula de Westphal. Pero no deberíamos dejarnos engañar por todo este fervor de innovación terminológica. A pesar de los nombres de última moda, la condición que los doctores se ocuparon de construir como orientación pervertida compartía una gran cantidad de características con el carácter desviado que había sido atribuido desde tiempos inmemoriales a la figura estigmatizada de los kinaidos o cinaedus, los mollis, los "catamitas", los "afectados" [pathics], "minion" o "molly"36. Fue esta antigua figura, esta venerable categoría de opinión "popular", la que fue reconstruida, por medio de un sofisticado aparato conceptual de sexología moderna, en una nueva clasificación de desviación sexual y de género, una orientación psicosexual.

\footnotetext{
${ }^{35}$ Ver, sobre este tema, la discusión que propone Moore (1997: 72-74).

36 Por supuesto, el molly mismo es una figura compleja, ya al borde del "homosexual", como han mostrado Trumbach y otros autores. En primer lugar, los mollies claramente tienen sexo con otros mollies. No quiero implicar que haya que pasar por alto las cuestiones interpretativas polémicas; simplemente deseo señalar que la figura del molly -no importa cuán adelantada al futuro pueda parecer en otros aspectos- retiene muchos de los rasgos tradicionalmente atribuidos a los varones invertidos o pasivos.
} 
Pero la inversión sexual, si fue además una orientación, todavía no se equiparaba a la homosexualidad. Por "sentimiento sexual contrario", por ejemplo, se intentaba significar un sentimiento sexual contrario al sexo de la persona que lo experimentaba,es decir, el sentimiento de pertenecer a un sexo diferente del propio, así como el sentimiento de una atracción erótica en desacuerdo con el sexo al que uno pertenecía (porque su objeto era miembro del mismo sexo de uno y por lo tanto expresaba una actitud masculina o femenina propia de los miembros de un sexo diferente del propio). Westphal, como muchos de sus contemporáneos, no distinguió sistemáticamente entre desviación sexual y desviación de género. La atracción hacia miembros del propio sexo indicaba una identificación con el sexo opuesto, y una identificación con el sexo opuesto algunas veces se expresaba a sí mismo como un sentimiento de atracción hacia los miembros del propio sexo. En este sentido, Westphal estaba reproduciendo las asunciones de su propia cultura, pero también había sido influido por los argumentos de Karl Heinrich Ulrichs [1825-1895], el primer activista político por la emancipación de las minorías sexuales, al que cita en su artículo, y quien en una serie de escritos compuestos desde 1862 describió su propia condición como la de una "anima muliebris virili corpore inclusa", un "alma de mujer atrapada en un cuerpo de hombre" ${ }^{\prime 37}$.

De manera similar, el concepto de inversión sexual trató el deseo sexual y la elección de objeto del mismo sexo como tan solo uno de un número de síntomas patológicos exhibidos por aquellos que revertían, o "invertían", los roles sexuales generalmente considerados adecuados para su propio sexo. Tales síntomas, indicando una identificación masculina en la mujer y una identificación femenina en el hombre, comprendían muchos elementos diferentes de estilo personal, que iban desde los ideológicamente cargados (mujeres que tomaban un interés en la política y hacían campaña por el derecho a votar) hasta los triviales y bizarros (hombres a quienes les gustaban los gatos), pero la amenaza que los unía era la inversión del rol sexual o la desviación de género (Chauncey, 1989). La preferencia sexual por un miembro del propio sexo no fue claramente distinguida de otras formas de no conformidad con la propia identidad de género, tal como estaba definida por normas culturales dominantes de masculinidad y feminidad. Una implicación de este modelo, que los diferencia llamativamente de nociones de homosexualidad, es que los compañeros del mismo sexo que los invertidos convencionalmente masculinos y femeninos no eran necesariamente anormales o problemáticxs o desviadxs ellxs mismxs: el prostituto [hustler] identificado como hetero, o la mujer que se permite a sí misma ser complacida por una butch, está simplemente actuando en un guion sexual adecuado con unx compañerx inadecuadx y podría ser sexualmente normal en su propio derecho (como KrafftEbing mismo había enfatizado en el pasaje citado anteriormente), sin importar cuán criminal pudiera ser su conducta ${ }^{38}$.

${ }^{37}$ El estudio básico sobre Ulrichs es el de Kennedy (1988). Westphal cita a Ulrichs, bajo el seudónimo Numa numantius, en el artículo ya citado de 1870 "Die conträre Sexualempfindung".

${ }^{38}$ Mi explicación deriva de Chauncey (1989). Mucho antes que Krafft-Ebing, Westphal (1870: 108) enfatizó que no todos los casos de "lascivia antinatural" (la conducta criminalizada por el artículo 143 del código de ley criminal prusiano, que pronto se convertiría en el infame artículo 175 de código de ley del imperio germano) procedían de causas patológicas: así como es posible identificar algunos ladrones como resultado de compulsión patológica sin que eso implique que la mayoría de los ladrones están motivados por una enfermedad mental, del mismo modo la simple perversidad humana, y no una perturbación psicológica, provoca muchos casos de "lascivia antinatural". 
Si la pederastia o la sodomía fueron tradicionalmente entendidas como una preferencia sexual sin una orientación sexual, la inversión, por el contrario, fue definida como una orientación psicológica sin una sexualidad. Una nota al pie al final del artículo de Westphal enfatizó "el hecho de que el sentimiento sexual contrario no siempre involucra de manera coincidente la fuerza sexual como tal, sino simplemente el sentimiento de estar alienado, con la totalidad del ser interior, del propio sexo - un estadio menos desarrollado, por así decirlo, del fenómeno patológico" (Westphal, 1870: 107n). Para Westphal y sus colegas, el "sentimiento sexual contrario" o la inversión sexual era una condición esencialmente psicológica de disforia de género que afectaba la vida interior del individuo, una orientación no necesariamente expresada en la realización o disfrute de actos (homo)sexuales particulares. De hecho, el ejemplo estrella de Westphal de sentimiento sexual contrario de un hombre fue un individuo que evitaba estrictamente, o al menos declaraba evitar, todo contacto sexual con miembros de su propio sexo, que expresaba un marcado deseo sexual por mujeres, al que se diagnosticaba como víctima de sentimiento sexual contrario sobre la base de su estilo de género únicamente, no sobre la base de deseo homosexual ${ }^{39}$.

Este personaje resultó ser un tal "Aug. Ha.", que había sido arrestado en una estación de tren de Berlín en el invierno de 1868, a la edad de 27 años, vistiendo ropas de mujer. Había trabajado como sirviente para diversas casas, a menudo llevando atuendo femenino e incluso portando pechos falsos en algún momento; también había robado ropas de mujer y artículos de tocador de sus empleadores y había sido encarcelado por utilizar identidades falsas. Registros médicos habían notado la "conducta casi femenina del paciente, que habla con una voz ceceante en un tono afeminado". Westphal se reunió con él y lo examinó personalmente. Describió a Ha. como "poderosamente construido" y "bien alimentado", alto, rasurado, con músculos bien desarrollados y cuerpo voluminoso, rasgos regulares, y cabello grueso, largo, rubio, un poco rizado, aunque Westphal pensaba que sería posible discernir "algo femenino" en las características faciales del paciente. Anatómicamente, Aug. Ha. no era muy exótico. El examen físico no reveló "deformidad particular alguna" en las orejas (aunque los lóbulos llevaban huellas de perforación), y abundante vello corporal, con pelo púbico hasta el ombligo. El escroto y la piel del pene eran fuertemente pigmentados y arrugados; los testículos eran "solo de tamaño moderado"; el ano no exhibía "nada especial".

Yendo al punto, Ha. sostenía que "nunca se dejó usar por hombres y nunca se ocupó de ellos en un sentido sexual, aunque le habían llegado muchas ofertas en esta dirección". Él había tenido simplemente una fuerte "inclinación" o "impulso" (sus propias palabras [Neigung, Trieb] a vestirse como mujer desde que tenía ocho años y había sido castigado a menudo por su madre por ponerse sus ropas. Siempre había tenido buena relación con las mujeres en su juventud y había salido a bailar con ellas mientras vestía ropas de mujer. Tenía una inclinación (de nuevo, su propia palabra, Neigung) a cultivar relaciones sexuales con mujeres, aunque raramente, por miedo de volverse repulsivo".

\footnotetext{
${ }^{39}$ Westphal (1870: 98) acepta la afirmación del sujeto de su sexualidad normal sobre la base de su propio testimonio y del hecho independiente de que al momento de su arresto se descubrió que padecía gonorrea (que Westphal, como Karl Maria Kertbeny, en este sentido, evidentemente creía que no podía transmitirse por sexo homosexual). Lejos de ser un bochorno o un obstáculo para el diagnóstico, el deseo heterosexual del sujeto está enfatizado en el relato de Westphal.
} 
Siguió ocupándose a sí mismo en tejer, bordar ropas y fabricar pequeños sombreros de mujer, mientras estaba bajo observación en el hospital. Westphal solicitó y tuvo éxito en conseguir su libertad, pero cuando su verdadera identidad se volvió conocida, Ha. fue arrestado y procesado a la luz de sus primeros robos, y en la época de redacción del libro cumplía una sentencia de dos años por reincidencia en la prisión de Brandenburgo (Westphal, 1870: 82-91 y 97-100) ${ }^{40}$.

La inversión sexual no representa, entonces, la misma noción que homosexualidad, porque la elección del objeto sexual del mismo sexo o el deseo homosexual no es esencial para ella. Uno puede ser invertido sin ser homosexual y uno puede tener sexo homosexual, ya sea como pederasta o sodomita, sin calificar como sexualmente invertido: de acuerdo con los criterios de la psiquiatría del siglo XIX, uno sería meramente perverso, no pervertido. Aquí Kinsey (que estaba versado en estos conceptos) insistió en que "la inversión y la homosexualidad son dos tipos de comportamiento diferentes y no siempre correlacionados" (1948: 615) ${ }^{41}$. En su lugar, las nociones de sentimiento sexual contrario e inversión sexual parecen mirar atrás a la larga tradición de la pasividad masculina estigmatizada, el afinamiento y la desviación de género, que focalizan menos en el sexo o en el deseo homosexual per se, que en una concomitante falta de masculinidad normativa en uno o ambos compañeros ${ }^{42}$.

$$
\star \star \star
$$

Ahora, por fin, llegamos a la homosexualidad, una categoría cuyas características y ramificaciones peculiares y distintivas destacarán, espero, mucho más claramente, en contraste con las cuatro tradiciones discursivas ya discutidas. La palabra "homosexualidad" apareció impresa por primera vez en Alemania en 1869, en dos panfletos anónimos publicados en Leipzig por un traductor austríaco de literatura húngara que tomó el nombre de Karl Maria Kertbeny. Aunque Kertbeny declaró pública-

${ }^{40}$ Me fue de enorme utilidad el trabajo inédito de Robert Grimm "The Dawn of Contrary Sexual Sensitivity" (Universidad de Washington), que cita, traduce y discute varios de los pasajes citados aquí.

${ }^{41}$ Para una elaboración detallada de la distinción entre homosexualidad e inversión, ver Tripp (1975: 22-35).

42 En este aspecto, al menos, Kinsey prueba ser un historiador más confiable que Foucault. En Historia de la sexualidad, Foucault (2005: 57) dató el nacimiento de la homosexualidad (como categoría discursiva) en el artículo de Westphal: "No hay que olvidar que la categoría psicológica, psiquiátrica, médica, de la homosexualidad se constituyó el día en que se la caracterizó -el famoso artículo de Westphal sobre las "sensaciones sexuales contrarias" (1870) puede valer como fecha de nacimiento- no tanto por un tipo de relaciones sexuales como por cierta cualidad de la sensibilidad sexual, determinada manera de invertir en sí mismo lo masculino y lo femenino. La homosexualidad apareció como una de las figuras de la sexualidad cuando fue rebajada de la práctica de la sodomía a una suerte de androginia interior, de hermafroditismo del alma. El sodomita era un relapso, el homosexual es ahora una especie". Creo que Foucault acertaba al ver en Westphal la emergencia de una noción psiquiátrica moderna de orientación erótica, que trae aparejada una especificación de individuos desviados y un desplazamiento desde un discurso jurídico de actos prohibidos a un discurso normalizador de psicología pervertida. Pero creo también que Foucault estaba equivocado al identificar la categoría de Westphal de "sentimiento sexual contrario" con la homosexualidad. En Epistemología del armario, Sedgwick (1990: 46) ingeniosamente argumenta que mi "lectura de la 'homosexualidad' como 'la comprendemos actualmente' es virtualmente lo opuesto de la de Foucault", en la medida en que Foucault tenía una comprensión de "género transitivo" de la homosexualidad, mientras que yo tengo una de "género intransitivo". Esto bien podría explicar por qué Foucault no toma lo que yo considero como el paso históricamente necesario de diferenciar sistemáticamente la "inversión sexual" de la "homosexualidad". Aun así, la cuestión principal aquí podría no ser una diferencia de opinión sobre lo que es la homosexualidad, sino una incertidumbre sobre si es posible esbozar una distinción significativa en la historia de los discursos modernos europeos entre "orientación" y "sexualidad". 
mente ser "sexualmente normal", su término "homosexualidad" puede ser considerado una acuñación originalmente progay, en la medida en que el autor lo usó en el curso de una fracasada campaña política para prevenir que el sexo homosexual fuera criminalizado por la recientemente formada Federación de Estados Alemanes del Norte.

A diferencia de "sentimiento sexual contrario", "inversión sexual" y "amor uránico", "homosexualidad" no fue acuñada para interpretar el fenómeno que describía o para adjuntarle una particular teoría médica o psicológica, y Kertbeny mismo se opuso vehementemente a los modelos de deseo homosexual de inversión o tercer sexo. "Homosexualidad" se refería, sencillamente, a una fuerza sexual dirigida hacia personas del mismo sexo que el sexo de la persona empujada por esa fuerza. Ciertamente, fue el mismo minimalismo del término, considerado desde una perspectiva teórica, el que lo hizo tan fácilmente adaptable por escritores y teóricos posteriores con una variedad de propósitos ideológicos. Como resultado, el término ahora condensa una gran cantidad de nociones diferentes sobre la atracción por el mismo sexo, así como una gran cantidad de modelos conceptuales diferentes sobre lo que es la homosexualidad.

Específicamente, "homosexualidad" absorbe y combina al menos tres conceptos diferentes y previamente no correlativos: (1) una noción psiquiátrica de orientación pervertida o patológica, derivada de Westphal y sus colegas del siglo XIX; un concepto esencialmente psicológico que se aplica a la vida interior del individuo y que no necesariamente presume comportamiento homosexual; (2) una noción psicoanalítica de deseo o elección de objeto sexual del mismo sexo, derivada de Freud y sus compañeros; una categoría de intencionalidad erótica que no necesariamente implica una orientación sexual permanente, tampoco desviada o patológica (puesto que, según Freud, la mayoría de los individuos hace una elección inconsciente del objeto homosexual en algún punto en sus vidas); y (3) una noción sociológica de conducta desviada sexualmente, derivada de las investigaciones forenses de los siglos XIX y XX sobre los "problemas sociales", que se centra en prácticas sexuales poco corrientes y que no alude necesariamente a la psicología erótica ni a la orientación sexual mostrada (puesto que la conducta sexual hacia personas del mismo sexo, como señalara Kinsey, no es ni propiedad exclusiva de quienes tienen una orientación sexual homosexual ni es patológica necesariamente, ya que se encuentra ampliamente representada en la población). De manera que ni una noción de orientación, ni una noción de elección de objeto, ni una noción de comportamiento bastan separadamente para generar la definición moderna de la homosexualidad; más bien, la noción parece depender de la inestable conjunción de las tres. La homosexualidad es, a la vez, una condición psicológica, un deseo erótico y una práctica sexual (tres cosas bastante diferentes entre sí).

Es más, la noción misma de homosexualidad implica que la expresión y sentimiento sexual por el mismo sexo, en todas sus variadas formas, constituye una única cosa llamada "homosexualidad", que puede ser considerada como un fenómeno singular, integrado, diferente y separado de la "heterosexualidad". La "homosexualidad" se refiere a todo comportamiento y deseo sexual por el mismo 
sexo, sea jerárquico o mutuo, polarizado genéricamente o no generizado, latente o real, mental o físico. Y, quizás lo más importante de todo, hace funcionar la elección de objeto homosexual como el marcador de la diferencia sexual y social.

La originalidad de "homosexualidad", como categoría y como concepto, aparece más vívidamente bajo esta luz. Los discursos anteriores, ya sean de sodomía o inversión, se referían a solo uno de los compañeros sexuales: el compañero "activo" en el caso de la sodomía, el varón afeminado o la mujer masculina en el caso de la inversión. El/la otrx compañerx, que no estaba motivadx por deseo sexual o que no era genéricamente desviadx, no calificaba para la inclusión en la categoría. "Homosexualidad", por contraste, se aplica a Ixs dxs compañerxs, ya sean activxs o pasivxs, ya sean genéricamente desviadxs o normativxs. El sello distintivo de la "homosexualidad", de hecho, es la negativa a distinguir entre compañerxs sexuales del mismo sexo, o clasificarlxs tratando a unx como más (o menos) homosexual que el/la otrx.

Kinsey puede ser considerado como representativo de esta perspectiva moderna. Rechazando como "propaganda" la tendencia de algunos hombres a definir su propia identidad sexual de acuerdo con un rol específico, un modelo pre-homosexual -considerarse a sí mismos heterosexuales porque solo recibían fellatios de otros hombres y no las practicaban ellos mismos- Kinsey escribió que todo "contacto sexual con otros hombres" que resultaba en un orgasmo era "por estricta definición... homosexual" (Kinsey, Pomeroy y Martin, 1948: 612 y 616). De acuerdo con Kinsey, en otras palabras, no importa quién se la chupe a quién. Contacto entre personas del mismo sexo es todo lo que se requiere.

En este sentido, la homosexualidad, en tanto concepto y práctica social, reafirma y reinterpreta significativamente patrones anteriores de organización erótica, y como tal, posee un número adicional de importantes consecuencias prácticas. En primer lugar, bajo la égida de la homosexualidad, la significación del género y de los roles de género para la categorización de actos y actores sexuales se difumina $\left[\right.$ fades] ${ }^{43}$. Un efecto del concepto de homosexualidad es separar la elección de objeto sexual del mismo sexo de toda conexión necesaria con la identidad de género, posibilitando adscribir la homosexualidad a mujeres y a hombres cuyos estilos de género y apariencia o modales exteriores son perfectamente normativos.

Sin dudas, esta transformación conceptual no ha sido absoluta. Mucha gente actualmente, tanto gay como no gay, continúa señalando una conexión entre desviación de género y homosexualidad. A pesar del predominio de las categorías de homosexualidad y heterosexualidad, las mujeres activas y los hombres pasivos, así como los hombres afeminados y las mujeres masculinas, todavía son consideradxs, en cierta medida, más homosexuales que otras personas, menos evidentemente desviadxs,

\footnotetext{
${ }^{43}$ La palabra acertadamente elegida "se desvanece" [fades] deriva de Adam (1985: 111), quien escribe: "Ias definiciones de rol sexual se desvanecen de la vinculación interpersonal". Este párrafo y mucho de lo que sigue a continuación ha sido inspirado por Adam.
} 
que escogen objetos sexuales del mismo sexo. Podemos aquí discernir la fuerza con que anteriores categorías sexuales pre-homosexuales continúan ejerciendo su autoridad dentro del universo conceptual más nuevo de homo- y heterosexualidad.

Un segundo efecto de la hegemonía del modelo reciente de homo-/ heterosexualidad ha sido la minimización de la significación taxonómica de los roles sexuales. Incluso los más asimétricos comportamientos pueden ser superados para los propósitos de clasificación sexual por la igualdad o diferencia de los sexos de las personas involucradas. Obsérvese la ansiedad expresada en la siguiente carta anónima enviada a un columnista de consejos sexuales en un periódico alternativo:

Soy $200 \%$ heterosexual, casado con hijos. Hace cosa de seis meses fui a un masajista que terminó el asunto con una descomunal mamada. Si me preguntas por qué no lo frené, la verdad es que no habría podido, porque él me masajeaba el culo con su dedo pulgar mientras me hacía sexo oral. Fue tan bueno que tuve que volver a este chico casi cada semana, no por el masaje sino por la mamada. Ahora estoy empezando a preocuparme de que esto me pueda etiquetar como gay. No estoy interesado en hacerle sexo oral a este chico, pero me pregunto si el que lo recibe es tan culpable como el que lo da. (citado por Savage, 1998: 189-190)

La preocupación del autor de la carta es un efecto directo de los discursos emergentes de la sexualidad y de los recientes cambios en la clasificación sexual que estos han introducido. Ninguna ansiedad de este tipo ataca a quienes todavía permanecen intactos a los discursos de la sexualidad ${ }^{44}$. El modelo homo/heterosexual ha tenido otras consecuencias también. La homosexualidad traduce las relaciones sexuales del mismo sexo al registro de la igualdad y mutualidad. Las relaciones homosexuales ya no implican más, necesariamente, una asimetría de identidades sociales o posiciones sexuales, ni se articulan, inevitablemente, en términos de jerarquía de poder, edad, género o rol sexual, lo que, de nuevo, no significa declarar que tales jerarquías no continúen funcionando significativamente en las sociedades lesbianas o gais, o que no estructuren las relaciones de diferentes formas de parejas lesbianas y gais: en algunos círculos todavía importa mucho quién chupa -o cogea quién ${ }^{45}$. Sin embargo, las relaciones homosexuales no son necesariamente desiguales en su distri-

\footnotetext{
44 Ver, además, Kinsey, Pomeroy y Martin (1948), (1985/1986: 294-317) y, MCleod y Nott (1994).

45 Ver Adam (2000), así como los datos sobre hombres gais de Londres y Cardiff recolectados por Coxon (1996: esp. 94-96). Aunque este autor observa que "si un hombre se involucra en una práctica sexual particular es más probable que lo haga en las dos modalidades, activa y pasiva (incluso en un periodo de un mes), más que restringirse a solo una de ellas"; también destaca algunas "interesantes tendencias contrarias" que incluyen una excepcional "rigidez de rol" en el caso de intercambio anal en que "aquellos que eran exclusivamente activos o exclusivamente pasivos ahora igualan o superan a los que son ambas cosas". Incluso Coxon, sin embargo, concluye que sus "resultados no respaldan la idea de que, incluso en un periodo de un mes, los hombres gais tienden a ser exclusivamente activos o pasivos durante el intercambio anal", y cita un estudio alemán que sugiere que el porcentaje de hombres gais que intercambian roles podría ser significativamente más grande en Amsterdam. De manera similar, el intercambio de roles parece ser la norma todavía hoy en las relaciones gais masculinas en Australia, de acuerdo con Dowset (1996: 81): "Aunque hubo una firme preferencia entre algunos hombres gais [en el grupo estudiado] en su afirmación de 'disfrute' sexual por el modo insertivo o receptivo en el intercambio anal, en la práctica tal actividad es comúnmente recíproca, con los hombres moviéndose del modo
} 
bución de placer o deseo erótico. Además, como la noción de amor romántico heterosexual, la noción de homosexualidad implica que es posible, para ambos compañeros, unirse el uno al otro no sobre la base de sus diferencias, sino de su igualdad, su identidad de deseo y orientación y "sexualidad". Las relaciones homosexuales dejan de estar estructuradas compulsivamente por una polarización de identidades y roles (activo/pasivo, insertivo/receptivo, masculino/ femenino, hombre/ muchacho). El amor homosexual exclusivo, para toda la vida, de compañerismo, romántico y mutuo se vuelve posible para los dos compañeros. Las relaciones homosexuales no están organizadas únicamente de acuerdo con los requerimientos o prescripciones de instituciones sociales a mayor escala, tales como sistema de parentesco, clases de edad o rituales de iniciación; más bien, funcionan como principio de organización social en su propio derecho, y dan lugar a relaciones sociales independientes (Adam, 1985).

La homosexualidad se establece ahora contra la heterosexualidad. La elección de objeto homosexual, por sí misma, es vista como un marcador de diferencia de la elección de objeto heterosexual. Homo y heterosexualidad han devenido formas de subjetividad humana más o menos mutuamente exclusivas, diferentes clases de sexualidad humana, y cualquier sentimiento o expresión de deseo heterosexual es considerada excluyente de cualquier sentimiento o expresión de deseo homosexual por parte del mismo individuo (con excepción de lxs bisexuales que son consideradxs, en consecuencia, como pertenecientes a una sexualidad enteramente separada). Dado que la elección de objeto sexual se vincula con una noción de orientación sexual, tal comportamiento sexual es visto como expresivo de una subyacente característica psicosexual permanente del sujeto humano. Por lo tanto, la gente es rutinariamente asignada a una u otra especie sexual sobre la base de su orientación y elección de objeto sexual.

insertivo al receptivo a su antojo". Las conclusiones de Dowset han sido masivamente confirmadas por una revisión reciente de la literatura empírica sobre intercambio anal alrededor del mundo realizada por Smith (2001), quien descubre que "entre varones activos predominantemente homosexuales identificados como gais que se involucran en intercambio anal, la mayoría son tanto activos como pasivos", y subraya que este descubrimiento se mantienen constante en estudios de sociedades pertenecientes al así llamado Occidente post-industrial" Ilevados a cabo "desde mediados de los años 60 hasta finales de los años 90".

Es posible que tales resultados hayan sido exagerados, o su significación sobredimensionada, quizás debido al disgusto con que los hombres gais supuestamente "liberados" ven el juego de roles rígidos. Más aun, Smith me previno (en un email del 7 de agosto de 2001) de que los datos cuantitativos sobre intercambio anal entre hombres gais no deberían ser considerados como indicadores de idéntica preferencia por el rol insertivo y receptivo, dado que en esos datos no se asigna frecuencia o predilección (en otras palabras, puede haber muchos más pasivos y activos que los que están reflejados en los datos cuantitativos sobre práctica sexual). El dr. Sasho Lambevski, investigador del National Centre in HIV Social Research at the University of New South Wales de Sydney, me escribe (en un e-mail del 13 de abril de 2000) como sigue: "Deduzco de mi propia investigación empírica y de la investigación de mis colegas, que las declaraciones de reciprocidad en los roles sexuales/de género en las relaciones gais están sumamente exageradas. En las entrevistas que hemos hecho con parejas gais, los gestos falsos con que los entrevistados responden a los nobles ideales de la liberación gay (reciprocidad, versatilidad, etc.) sirven como una estrategia retórica para cubrir la tensión real entre compañeros causada por diversas formas de desequilibrios de poder (en su mayoría de género)". Lambevski remite al trabajo de Smith y Kippax (2001), quienes argumentan, sin embargo, no que la reciprocidad haya sido exagerada, sino que su mera existencia no borra la significación de jerarquías en prácticas de intercambio anal en relaciones gais masculinas, destacando que "en las culturas occidentales pervive una distinción conceptual entre los compañeros insertivos y receptivos que marca a la persona receptiva como femenina y a la insertiva como masculina". Sinfield (2000: 27) ve la persistencia de jerarquías sociales en las relaciones gais como elemento que socava el supuesto triunfo del modelo "igualitario" de la homosexualidad "moderna". 
En suma, la homosexualidad es más que la elección sexual de un objeto del mismo sexo, más incluso que la consciente preferencia erótica por el mismo sexo. La homosexualidad es, por sí sola, la especificación de una elección de objeto sexual del mismo sexo como un principio esencial de diferencia sexual y social. La homosexualidad es parte de un nuevo sistema de sexualidad, que funciona como un medio de individuación personal: asigna a cada individuo una orientación sexual y una identidad sexual. Como tal, la homosexualidad introduce un nuevo elemento en la organización social, en la articulación social de la diferencia humana, en la producción social del deseo y, en última instancia, en la construcción social del ser.

Sería fácil comprender algunas de las características superpuestas y peculiares de las cinco tradiciones discursivas en la historia de la clasificación de la clasificación (homo)sexual consultando la tabla que sigue. Como esta comparación esquemática indica, cada una de las cinco tradiciones es irreductible a las otras. No me interesa defender la corrección o incorrección de las respuestas individuales que he dado a mis propias preguntas (reconozco que mis respuestas son discutibles); más bien, deseo mostrar, por medio de las respuestas afirmativas y negativas dispersas a lo largo de la gráfica, que los patrones que he descrito no se reducen a un esquema único y coherente.

Un modo de darle sentido a esta tabla es notar la radical diferencia entre la categoría inicial -homosexualidad- y las otras cuatro. Las cuatro categorías tradicionales, posclásicas, o de larga duración ("afeminamiento", "pederastia/sodomía", "amistad/amor", "pasividad/inversión") dependen crucialmente de nociones de género. Esto es obvio en el caso del afeminamiento y pasividad/ inversión, pero también es verdad en el caso de la pederastia/sodomía y amistad/amor, puesto que están definidos por la encarnación y performance, por parte del sujeto masculino, de normas tradicionalmente masculinas y masculinizantes, del mismo modo que afeminamiento y pasividad/inversión se definen por la violación de esas normas. En estos sistemas tradicionales de sexo y género, la noción de "sexualidad" es prescindible porque la regulación de conductas y estatus sociales se alcanza a través del sistema de género únicamente.

\section{LAS CINCO CATEGORÍAS}

\begin{tabular}{|c|c|c|c|c|c|}
\hline & Homosexualidad & Afeminamiento & Sodomía & Amistad & Inversión \\
\hline $\begin{array}{l}\text { ¿Es una } \\
\text { orientación? }\end{array}$ & Sí & No & $\begin{array}{l}\text { No en } \\
\text { realidad }\end{array}$ & No & Sí (¿?) \\
\hline $\begin{array}{l}\text { ¿lmplica } \\
\text { desviación de } \\
\text { género? }\end{array}$ & Quizá & Sí & No (i?) & No & Sí \\
\hline $\begin{array}{l}\text { ¿Implica contacto } \\
\text { genital entre } \\
\text { personas del } \\
\text { mismo sexo? }\end{array}$ & En general & $\begin{array}{l}\text { No } \\
\text { necesariamente }\end{array}$ & En general & No (i?) & A veces \\
\hline
\end{tabular}




\begin{tabular}{|l|l|l|l|l|l|}
\hline $\begin{array}{l}\text { ¿Es una } \\
\text { preferencia } \\
\text { sexual? }\end{array}$ & Sí & No & A veces & No & $\begin{array}{l}\text { No en } \\
\text { realidad }\end{array}$ \\
\hline $\begin{array}{l}\text { ¿Representa un } \\
\text { tipo de carácter? }\end{array}$ & Quizá & Sí & No (¿?) & No & Sí \\
\hline $\begin{array}{l}\text { ¿Implica deseo } \\
\text { homoerótico? }\end{array}$ & Sí & A veces & $\begin{array}{l}\text { Sí, al } \\
\text { menos } \\
\text { para uno } \\
\text { de los dos }\end{array}$ & Quizá & No \\
\hline $\begin{array}{l}\text { ¿Clasifica } \\
\text { conjuntamente a } \\
\text { hombres y } \\
\text { mujeres? }\end{array}$ & Sí & No & No & No (¿?) & Sí \\
\hline $\begin{array}{l}\text { ¿Es constante a } \\
\text { través de la } \\
\text { transición sexual } \\
\text { o el género? }\end{array}$ & Quizá & No & No & No & No \\
\hline
\end{tabular}

Por supuesto, el estatus social y la clase también contribuyen a la producción de las cuatro categorías finales. Por ejemplo, el afeminamiento se aplica especialmente a aquellos hombres que están en un nivel lo suficientemente alto en rango y estatus como para ser susceptibles de sufrir una pérdida o reducción en el rango al actuar en discrepancia con el comportamiento esperado por la élite. La amistad/amor demanda una igualdad de rango entre los compañeros, mientras que pederastia/ sodomía depende de una diferencia social significativa entre los compañeros respecto a la edad, estatus y rol sexual. La pasividad/inversión se define a sí misma en relación con la jerarquía de género. Con el arribo de la homosexualidad, los sistemas de diferencia que fueron internos a la estructura de las primeras cuatro categorías se ven a sí mismos externalizados y reconstituidos en el borde entre homosexualidad y heterosexualidad, categorías que ahora representan en y por sí mismas nuevas formas de diferenciación y regulación social y nuevos modos de regular y reforzar las normas de género. Las categorías homo/hetero operan no para mantener una ya existente jerarquía de género sexual y de estatus, sino para manejar, mediante la diferenciación y la disciplina, masas desordenadas de individuos nocionalmente idénticos. Un nombre para esta técnica de gobierno de los individuos en masa mediante diferenciación y comparación es normalización ${ }^{46}$.

${ }^{46}$ Ver Foucault (2008: 213): "En suma, el arte de castigar, en el régimen de poder disciplinario [...] utiliza cinco operaciones bien distintas: referir los actos, los hechos extraordinarios, las conductas similares a un conjunto que es a la vez campo de comparación, espacio de diferenciación y principio de regla a seguir. Diferenciar a los individuos unos respecto de otros y en función de esta regla de conjunto -ya se la haga funcionar como umbral mínimo, como medio que respetar o como grado óptimo al que hay que acercarse-. Medir en términos cuantitativos y jerarquizar en términos de valor las capacidades, el nivel, la 'naturaleza' de los individuos. Hacer que entre en juego, a través de esta medida 'valorizante', la coacción de una conformidad que realizar. Y, por último, trazar el límite que habrá de definir la diferencia respecto de todas las diferencias, la frontera exterior de lo anormal. [...] [Esto] compara, diferencia, jerarquiza, homogeniza, excluye. En una palabra, normaliza. [...] Como la vigilancia, y junto a ella, la normalización se torna uno de los grandes instrumentos de poder al final de la época clásica. Se tiende a sustituir, o al menos a agregar, a las marcas que traducían estatus, privilegios, adscripciones, todo un juego de grados de normalidad que son signos de pertenencia a un cuerpo social homogéneo, pero que tienen en sí mismos un papel de clasificación, de jerarquización y de distribución de los rangos. En un sentido, el poder de normalización obliga a la homogeneidad; pero individualiza al permitir las desviaciones, determinar los niveles, fijar las especialidades y hacer útiles las diferencias ajustándolas unas a otras. Se comprende que el 
Hay una ironía en el sexo. Me refiero a una ironía diferente de las que ya conocemos, producidas por todas las desproporciones tragicómicas entre el amor y sus objetos, entre sentimiento y expresión, entre deseo y demanda. Porque la palabra "sexo", en sí, puede derivar del latín "secare", "cortar o dividir": originalmente significaba la nitidez y claridad de las divisiones entre categorías naturales de varón y mujer. Y sin embargo, "sexo" ha llegado a un límite de significado tan zarandeado por cambios históricos y reestructuraciones en los conceptos y formas de la vida sexual, que ahora representa lo que es más resistente a la clasificación, discriminación y división claras.

Más particularmente, la emergencia de la homosexualidad como categoría ha hecho difícil para nosotros comprender las modalidades anteriores de clasificación sexual y genérica en toda su riqueza y especificidad. También ha complicado nuestra tarea de comprensión de la significación de diversas asimetrías actuales en el seno de las relaciones, patrones de preferencia o prácticas homosexuales que se desvían de los estándares ideales de reciprocidad, igualdad e identidad de género impuestas por la fuerza cripto-normativa de la categoría homosexual misma. ¿Cómo entender ahora el rol que desempeñan las diferencias percibidas en torno a la edad, al estilo de género, al rol sexual, al tipo de cuerpo, a la clase social, a la etnia, a la raza, a la religión y/o a la nacionalidad en la estructuración, aunque sea parcial, de las relaciones de algunas parejas de lesbianas y de gais? Tales diferencias entre Ixs compañerxs a menudo se vuelven poderosamente significativas, tanto para Ixs compañerxs mismxs como para quienes vienen a estar en contacto con ellxs, pero ya no resulta muy claro cómo operan estas diferencias para construir formas actuales de vida gay y lesbiana, o cuál es su significado estructural al modelar las sexualidades contemporáneas gais y lesbianas.

En el capítulo "Historia" de su libro sobre Oscar Wilde [¿Quién fue ese hombre? Un presente para Mr. Oscar Wilde, 1988], indudablemente la más brillante y original exploración sobre cómo hacer la historia de la homosexualidad masculina, Neil Bartlett pondera la relación entre formaciones de existencia homosexual pasadas y presentes en los siguientes términos, y no se me ocurre un modo mejor de concluir que citarlo: ${ }^{47}$

\section{'¿Qué clase de hombre fue?'}

Es decir, ¿qué clase de hombres somos nosotros?

[...] Mirando a este hombre en sus zapatos de taco alto, el vestido negro cayendo de uno de sus hombros (era tarde en la noche), recuerdo que él y sus hermanas han estado haciendo lo suyo como damas de la noche [en Londres] desde 1870,

poder de la norma funcione fácilmente en el interior de un sistema de igualdad formal, ya que, en el interior de una homogeneidad, que es la regla, introduce, como un imperativo útil y el resultado de una medida, toda una gradación de diferencias individuales". Esta cita corresponde a la traducción española de Surveiller et punir consignada en la bibliografía, y no a la traducción inglesa manejada por Halperin (nota de los traductores).

${ }^{47}$ El libro de Bartlett establece puntos de contacto entre los homosexuales londinenses de la década de 1980 y sus homólogos de un siglo antes: Oscar Wilde y sus amigos, amantes y conocidos. [N. T.] 
cuando Fanny y Stella iban al Strand ${ }^{48}$. Su vestido es heredado, de segunda mano, parte de una historia, de una tradición. Y que ese hombre esté comprando a su joven novio (ligeramente incómodo, pero felizmente borracho) otro trago -recuerdo la bizarra mezcla de mitologías que Wilde utilizó para justificar su adoración por los muchachos jóvenes, la fusión de un pastiche de la pederastia griega con un fervor misionero por las "clases criminales", el sentido en que ellos, no los muchachos que dejó durmiendo en [su casa en] Chelsea, fueron sus verdaderos hijos- ¿podría yo olvidar todo eso, avergonzarme a mí mismo? ¿Podría mirar para otro lado? ¿Podría desdeñar todo eso simplemente porque ahora, como entonces, un hombre está pagando por otro? ¿No hay un intento de crear una nueva forma de relación, un affaire del corazón en alguna medida apropiado para la unión de dos hombres verdaderamente diferentes? Esa es nuestra verdadera historia, la única que todavía estamos escribiendo. (Bartlett, 1988: 223)

Traducción: Jorge Luis Peralta y Juan Ariel Gómez.

Esta traducción forma parte del proyecto PID2019-106083GB-I00 del Ministerio de Ciencia e Innovación de España.

\section{Referencias bibliográficas}

Adam, Barry (1985), "Structural Foundations of the Gay World", Comparative Studies in Society and History, 27: 658-671.

. (1986), "Age, Structure, and Sexuality: Reflection on the Anthropological Evidence on Homosexual Relations", Antropology and Homosexual Beahaviour, Evelyn Blanckwood (ed.), New York, Haworth: 19-33.

. (2000), "Age Preferences among Gay and Bisexual Men", GLQ: A Journal of Gay and Lesbian Studies, 6.3: 413-434.

Bartlett, Neil (1988), Who Was That Man? A Present for Mr Oscar Wilde, London, Serpent's Tail.

Bartos, Michael, John McLeod y Phil Nott (1988), Meaning of Sex between Men: A Study Conducted by the Australian Federation of AIDS Organisations for the Commonwealth Department of Human Services and Health, Canberra, Australian Government Publishing Service.

Bennett, Judith M. (1997), "Confronting Continuity", Journal of Women's History, 9.3: 73-94.

Boswell, John (1980), Christianity, Social Tolerance, and Homosexuality: Gay People in Western Europe from the Beginning of the Christian Era to the Fourteenth Century, Chicago, Chicago University Press. (Traducción española: Cristianismo, tolerancia social y homosexualidad. Los gays en Europa occidental desde el comienzo de la Era Cristiana hasta el siglo XIV, traducido por M. A. Galmarini, Barcelona, Muchnik, 1992).

48 Para discusiones históricas recientes sobre el incidente al que Bartlett alude aquí, ver Cohen (1996: 73-129) y Kaplan (1999). 
Bray, Alan (1982), Homosexuality in Renaissance England, London, Gay Men's Press.

__ (1994), "Homosexuality and the Signs of Male Friendship in Elizabethan England", Queering the Renaissance, Jonathan Goldberg (ed.), Durham, Duke University Press: 40-61.

Bray, Alan y Michael Rey (1999), "The Body of the Friend: Continuity and Change in Masculine Friendship in the Seventeenth Century", English Masculinities 1660-1800, Tim Hitchcock y Michèle Cohen (eds.), London, Addison Wesley Longman: 65-84.

Cady, Joseph (1993), "Renaissance Awareness and Language for Heterosexuality: 'Love' and 'Feminine Love'", Renaissance Discourses of Desire, Claude Summers y Ted-Larry Pebworth (eds.), Columbia, Columbia University Press: 143-158.

. (1996), "The 'Masculine Love' of the 'Princes of Sodom' 'Practising the Art of Ganymede' at Henry III's Court: The Homosexuality of Henri III and His Mignon in Pierre de L'Estoile's Mémoires-Journaux", Desire and Discipline: Sex and Sexuality in the Posmodern West, Jacqueline Murray y Konrad Eisenbichler (eds.), Toronto, Toronto University Press: 123-156.

Chakrabarty, Dipesh (2000), Provincialing Europe: Postcolonial Thought and Historical Difference, Princeton, Princeton University Press.

Chariton (1989), Chaereas and Callirhoe, traducido por B. P. Reardon, Collected Ancient Greek Novels, B. P. Reardon (ed.), Berkeley, University of California Press.

Chauncey, George (1985-1986), "Christian Brotherhood or Sexual Perversion? Homosexual Identities and the Construction of Sexual Boundaries in the World War One Era", Journal of Social History, 19: 189-211.

__ (1989), "From Sexual Inversion to Homosexuality: Medicine and the Changing Conceptualization of Female Deviance", Passion and Power: Sexuality in History, Kathy Peiss y Christina Simmons, con Robert A. Padgug (eds.), Philadelphia, Temple University Press: 87-117.

Clark, Anna (1996), "Anne Lister's Construction of Lesbian Identity", Journal of History of Sexuality, 7: 23-50.

Cohen Jr., Samuel K. (1999), "Forbidden Friendships: Homosexuality and Male Culture in Renaissance Florence (1996) by Michael Rocke" (review), Speculum, 74: 481-483.

Cohen, William A. (1996), Sex Scandal: The Private Parts of Victorian Fiction, Durham, Duke University Press.

Coxon, Anthony P. M. (1996), Between the Sheets: Sexual Diaries and Gay Men's Sex in the Era of AIDS, London, Cassell.

Daniell, Rosemary (1984), Sleeping with Soldiers: In Search of the Macho Man, New York, Holt, Rinehart \& Winston.

Davidson, Arnold I. (1987a), "How to Do the History of Psychoanalysis: A Reading of Freud's Three Essays on the Theory of Sexuality", Critical Inquiry 13.2: 252-277.

- (1987b), "Sex and the Emergence of Sexuality", Critical Inquiry,14.1: 16-48.

(1900), "Closing Up the Corpses: Diseases of Sexuality and the Emergence of the Psychiatric Style of Reasoning", Meaning and Method: Essays in Honor of Hilary Putnam, George Boolos (ed.), Cambridge, Cambridge University Press: 295-325.

Dowsett, Gary W. (1996), Practicing Desire: Homosexual Sex in the Era of AIDS, Stanford, Stanford University Press.

Duberman, Martin, Marta Vicinus y George Chauncey Jr. (eds.) (1989), Hidden from History: Reclaiming the Gay and Lesbian Past, New York, New American Library. 
Foucault, Michel (1979), Discipline and Punish: The Birth of the Prison, traducido por Alan Sheridan, New York, Vintage. (Traducción española: Vigilar y castigar. Nacimiento de la prisión, traducido por A. Garzón del Camino, Buenos Aires, Siglo XXI, 2008).

- _ (1980), The History of Sexuality, vol. I, An Introduction, traducido por Robert Hurley, New York, Vintage. (Traducción española: Historia de la sexualidad I. La voluntad de saber, traducido por U. Guiñazú, Buenos Aires, Siglo XXI, 2005).

Gagnon, John H. y William Simon (1973), The Sexual Conduct: The Social Sources of Human Sexuality, Chicago, Aldine.

Gleason, Maud W. (1995), Making Men: Sophists and Self-Presentation in Ancient Rome, Princeton, Princeton University Press.

Greenberg, David F. (1988), The Construction of Homosexuality, Chicago, University of Chicago Press.

Haggerty, George (1999), Men in Love: Masculinity and Sexuality in the Eighteenth Century, New York, Columbia University Press.

Halperin, David M. (1990), One Hundred Years of Homosexuality and Other Essays on Greek Love, New York, Routledge.

_. (2002), How to Do the History of Homosexuality, Chicago-London, The University of Chicago Press.

_. (2003), "Sex, Sexuality, Sexual Classification", Critical Terms for Gender Studies, Catharine Stimpson y Gilbert Herdt (eds.), Chicago, University of Chicago Press: 449-486.

Herdt, Gilbert (1987), "Homosexuality", Encyclopedia of Religion, vol. 6, Mircea Eliade (ed.), New York, MacMillan: 445-452.

__ (1997), Same Sex, Different Cultures, Boulder, Westview.

Herrup, Cynthia B. (1999), A House in Gross Disorder: Sex, Law, and the Second Earl of Castlehaven, New York, New York University Press.

Jaeger, Stephen (1999), Ennobling Love: In Search of a Lost Sensibility, Philadelphia, University of Pennsylvania Press.

Kaplan, Morris B. (1999), "Who's Afraid of John Saul? Urban Culture and the Politics of Desire in Late Victorian London", GLQ: A Journal of Lesbian and Gay Studies, 5.3: 267-314.

Kennedy, Hubert (1988), The Life and Works of Karl Heinrich Ulrichs, Pioneer of the Modern Gay Movement, Boston, Alyson.

Kinsey, Alfred, Wardell B. Pomeroy y Clyde E. Martin (1948), Sexual Behaviour in the Human Male, Philadelphia, Saunders. (Traducción española: Conducta sexual del hombre, traducido por J. Clementi, Buenos Aires, Siglo Veinte.

Koehl, Robert B. (1986), "The Chieftain Cup and a Minoan Rite of Passage", Journal of Hellenic Studies, 106: 99-110.

_- (1997), "Ephoros and Ritualized Homosexuality in Bronze Age Crete", Queer Representations: Reading Lives, Reading Cultures, Martin Duberman (ed.), New York, New York University Press: 7-1.

Kulick, Don (1998), Travesti: Sex, Gender, and Culture among Brazilian Transgendered Prostitutes, Chicago, University of Chicago Press. 
Kunzel, Regina (2002), "Situating Sex: The Problem of Prison Sexual Culture in the Mid-TwentiethCentury U.S.", GLQ: A Journal of Lesbian and Gay Studies, 8.3: 253-270.

Loraux, Nicole (1990), "Herakles: The Super-Male and the Feminine", traducido por Robert Lamberton, Before Sexuality: The Construction of Erotic Experience in the Ancient Greek World, David M. Halperin, John J. Winkler y Froma I. Zeitlin (eds.), Princeton, Princeton University Press: 21-52.

MacAlister, Suzanne (1992), "Gender as Sign and Symbolism in Artemidoro's Oneirokritika: Social Aspirations and Anxieties", Helios, 19: 140-160.

Marshall, John (1981), "Pansies, Perverts and Macho Men: Changing Conceptions of Male Homosexuality", The Making of the Modern Homosexual, Kenneth Plummer (ed.), London, Hutchinson: 133-154.

Montaigne, Michel de (1958), The Complete Essays of Montaigne, traducido por Donald M. Frame. Standford, Standford University Press.

Moore, Lisa L. (1997), Dangerous Intimacies: Towards a Saphic History of the British Novel, Durham, Duke University Press.

Muecke, Frances (1984), "A Portrait of the Artist as a Young Woman", Classical Quarterly, 32: 41-55.

Murray, Jacqueline (1996), "Twice Marginal and Twice Invisible: Lesbian in the Middle Ages",

Handbook of Medieval Sexuality, Vern L. Bullough y James A. Brundage (eds.), London, Garland: 191-222.

Murray, Stephen O. (1984), Social Theory, Homosexual Realities, New York, Gay Academic Union. - (1989), "Homosexual Acts and Selves in Early Modern Europe", The Pursuit of Sodomy: Male Homosexuality in Renaissance and Enlightenment Europe, Kent Gerard y Gert Hekma (eds.), New York, Harrington Park Press: 457-477.

_- (1995), "Homosexual Categorization in Cross-Cultural Perspective", Latin American Male Homosexualities, Albuquerque, University of New Mexico Press: 3-31.

_- (2000), Homosexualities, Chicago, University of Chicago Press.

Olsen, Gren W. (1988), "St. Anselm and Homosexuality", Anselm Studies: An Occasional Journal (Special Issue: "Proceedings of the Fifht Internationl Saint Anselm Conference: St. Anselm and St. Augustine-Episcopi and Saecula". Ed. Joseph C. Schnaubelt et al.), vol. 2: 93-141.

Orgel, Stephen (1996), Impersonations: The Performance of Gender in Shakespeare's England, Cambridge, Cambridge University Press.

Ovesey, Lionel (1969), Homosexuality and Pseudohomosexuality, New York, Science House.

Posner, Richard A. (1992), Sex and Reason, Cambridge, Harvard University Press.

Pseudo-Lucian (1997), Erôtes, traducido por M. D. Mcleod, Lucian VIII, Cambridge, Harvard University Press.

Reiss, Albert (1961/1962), "The Social Integration of Queers and Peers", Social Problems, 9: 102-120.

Richlin, Amy (1993), "Not Before Homosexuality: The Materiality of Cinaedus and the Roman Law against Love between Men", Journal of the History of Sexuality, 3. 4: 523-57.

Rocke, Michael (1996), Forbidden Friendships: Homosexuality and Male Culture in Renaissance Florence, New York, New York University Pres. 
Rowson, Everett (1991), "The Categorization of Gender and Sexual Irregularity in Medieval Arabic Vice Lists", Body Guards: The Cultural Politics of Gender Ambiguity, Julia Epstein y Kristina Straub (eds.), New York: Routledge: 50-79.

Savage, Dan (1988), Savage Love: Straight Answers from America's Most Popular Sex Columnist, New York: Plume.

Schachter, Marc D. (2001), "'That Friendship Which Possesses the Soul': Montaigne Loves La Boétie", Journal of Homosexuality, 41. 3-4: 5-21.

Sedgwick, Eve Kosofsky (1990), Epistemology of the Closet, Berkeley, University of California Press. (Traducción española: Epistemología del armario, traducido por T. Bladé Costa, Barcelona, Ediciones de la Tempestad, 1998).

Sinfield, Alan (1998), Gay and After, London, Serpent's Tail.

. (2000), "The Production of Gay and the Return of Power", De-Centring Sexualities: Politics and Representations beyond the Metropolis, Richard Phillips, Diane Watt y David Shuttleton (eds.), London, Rouletdge: 21-36.

__. (2002), "Lesbian and Gay Taxonomies", Critical Inquiry, 29.1: 120-138.

Smith, Gary (2001), "Heterosexual and Homosexual Anal Intercourse: An International Perspective", Venereology, 14. 1: 28-37.

Smith, Gary y Susan Kippax (2001), "Anal Intercourse and Power in Sex between Men", Sexualities, 4: 413-434.

Tamassia, Arrigo (1878), "Sull' inversione dell' istinto sessuale", Rivista sperimentale di freniatria e di medicin legale, 4: 97-117.

Tripp, Clarence Arthur (1975), The Homosexual Matrix, New York, McGraw-Hill. (Traducción española: La cuestión homosexual, traducido por R. Lassaletta, Madrid, Edaf, 1978).

Trumbach, Randolph (1977), "London's Sodomites: Homosexual Behaviour and Western Culture in the Eighteenth Century", Journal of Social History, 11: 1-3.

_ . (1989), "The Birth of the Queen: Sodomy and the Emergence of Gender Equality in Modern Culture (1660-1750)", Hidden from History: Reclaiming the Gay and Lesbian Past, Martin Duberman, Marta Vicinus y George Chauncey Jr. (eds.), New York, New American Library: 129140 y $509-511$.

Vanggaard, Thorkil (1972), Phallos: A Symbol and its History in the Male World, traducido por Thorkil Vanggaard, New York, International Universities Press.

Westphal, C. (1870), "Die conträre Sexualempfindung, Symptom eines neuropathischen en (psychopathischen Zustandes)", Archiv für Psychiatrie und Nervenkrankheiten, 2: v73-108.

Williams, Craig A. (1999), Roman Homosexuality: Ideologies of Masculinity in Classical Antiquity, New York, Oxford University Press.

Wright, J. W. y Everett K. Rowson, Homoeroticism in Classical Arabic Literature, New York, New York University Press.

Zetilin, Froma I. (1996), "Travesties of Gender and Genre in Aristophane's Thesmophorizusae", Playing the Other: Gender and Society in Classical Greek Literature, Chicago, University of Chicago Press: 375-416. 